Oxford-Man Institute of Quantitative Finance

\title{
Time-varying liquidity in hedge fund returns
}

\section{Sheng Li Andrew J. Patton}




\title{
Time-Varying Liquidity in Hedge Fund Returns*
}

\author{
Sheng Li \\ Financial Markets Group \\ London School of Economics \\ Andrew J. Patton \\ Department of Economics and Oxford-Man Institute of Quantitative Finance \\ University of Oxford
}

This version: 30 May 2007

We propose a method for determining the factors that affect the (unobservable) liquidity of hedge fund investments. Our method exploits the link between illiquidity and serial correlation in hedge fund returns established by Getmansky, Lo and Makarov (2004), and does not require information on the actual positions taken by the hedge fund, nor even the 'style' of the hedge fund; we use only the returns reported by the hedge fund and other easily observed information. Using a panel of monthly returns on over 600 individual hedge funds, we find significant evidence of time variation in the degree of liquidity of hedge fund investments. Broadly stated, hedge funds in equity-based styles, such as equity market neutral and equity hedge or nonhedge, exhibit decreases in liquidity when stock market returns are low and bond market returns are high. In contrast, hedge funds in fixed income styles, such as convertible arbitrage or fixed income, exhibit lower liquidity when equity market volatility is high, and when the fund experiences in-flows or out-flows of funds.

Keywords: liquidity, serial correlation, return smoothing, hedge funds.

J.E.L. Codes: G23, G11, C22.

${ }^{*}$ Helpful comments and suggestions on this work were received from Giovanni Beliossi, Robert Kosowski, Kevin Sheppard, Michela Verardo, and seminar participants at the Adam Smith Asset Pricing workshop and Lancaster University. The authors gratefully acknowledge financial support for this research from Inquire UK. This article represents the views of the authors and not of INQUIRE UK. Contact address: Department of Economics, University of Oxford, Manor Road, Oxford OX1 3UQ, United Kingdom. Email: andrew.patton@economics.ox.ac.uk. This paper is available from http://www.economics.ox.ac.uk/members/patton/research.html. 


\section{Introduction}

The liquidity of hedge funds' investments is of great interest to hedge fund investors and to market regulators. The degree of investment liquidity directly affects the liquidity that the fund can offer its investor; funds with less liquid investments require longer "lock-up" and redemption notification periods from their investors in order to avoid costly exits from illiquid investments. Regulators have expressed much concern about the liquidity of hedge funds' investments and the potential market impact of the collapse of a fund ${ }^{1}$. The 1998 Long Term Capital Management crisis highlighted liquidity as a particularly important source of risk for hedge funds, for both investors and regulators.

Whilst there is much interest in hedge fund liquidity, it remains an elusive concept to measure and has a variety of definitions and interpretations. Most definitions suggest, in some way, that highly liquid markets are those where it is possible to trade large quantities of the asset quickly and at low cost. Measures of liquidity for standard assets include variables such as the bid-ask spread, the volume of turnover, and possibly the depth of the best bid and ask quotes. Using these, and other proxies for liquidity, the liquidity risk in stock and bond markets has been intensively studied $^{2}$. The liquidity risk of hedge funds has recently begun to attract attention, though the problem is complicated by the fact that the liquidity proxies used in studies of stock and bond markets are not directly applicable to hedge funds. The attention to hedge fund liquidity comes at an important time: the assets under management by hedge funds was estimated to have surpassed $\$ 1.4$ trillion at the end of 2006 , a $40 \%$ increase over the previous 12 months, and approximately a 28-fold increase since 1990.

A number of recent papers have studied the returns generated by hedge funds, though none of these studies directly focus on the liquidity risk of hedge funds ${ }^{3}$. Hedge fund liquidity, generally

\footnotetext{
${ }^{1}$ As pointed out by the new Chairman of the Federal Reserve Board at the Federal Reserve Bank of Atlanta's 2006 Financial Markets Conference: "Much of the recent debate...has focused on the opacity of hedge funds to regulatory authorities and to the markets generally, which is viewed by some as an important source of liquidity risk. Liquidity in a particular market segment might well decline sharply and unexpectedly if hedge funds chose or were forced to reduce a large exposure in that segment. Concerns about hedge fund opacity and possible liquidity risk have motivated a range of proposals for regulatory authorities to create and maintain a database of hedge fund positions."

${ }^{2}$ See Fleming (2003), Pástor and Stambaugh (2003), Fujimoto (2004), Avramov, et al. (2005), Chordia, et al. (2005), Goldreich, et al. (2005) and Johnson (2006), amongst others.

${ }^{3}$ Ackermann, McEnally, and Ravenscraft (1999), Agarwal and Naik (2000), Edwards and Caglayan (2001), Fung and Hsieh (1997, 2002) and Liang (1999, 2000, 2001) provide comprehensive studies of historical hedge fund per-
} 
considered, has various aspects. From the perspective of the investors in hedge funds, the "lock-up" and redemption notice periods are the sources of illiquidity of most concern. The lock-up period is the period that investors must wait before withdrawing their initial investment in the fund, and is usually on the order of one to eighteen months. The redemption notice period is the notification period required before investors can redeem their shares, which is usually one to three months. The main source of illiquidity from the perspective of the hedge fund manager is the liquidity of the fund's investments. As mentioned above, the liquidity of the fund's investments and that offered to the fund's investor's, in the form of lock-up and redemption periods, are connected: hedge funds with longer lock-up and redemption periods may invest in more illiquid assets, which may provide greater profit opportunities.

The two aspects of hedge fund liquidity have very different properties. The illiquidity imposed on hedge fund investors by the fund itself, through the lock-up and redemption notice periods, has two important properties: it is constant through time and is directly observable, both to the investor (of course) and to the researcher. The illiquidity caused by the fund's investments in illiquid assets, on the other hand, will generally not possess either of these properties: the degree of liquidity will not necessarily be constant, and the degree of liquidity is not directly observable.

Using the first type of liquidity as a risk measure, Aragon (2007) finds that liquidity helps explain expected hedge fund returns. He shows that there is a positive, concave relationship between a hedge fund's excess returns and its redemption notice period. He also documents that the difference in excess returns on lockup versus non-lockup funds is about $4 \%$ per annum in aggregate.

The study by Getmansky, Lo and Makarov (2004) (henceforth GLM) on possible sources of serial correlation in hedge fund returns helps shed light on the harder-to-measure illiquidity resulting from investments. GLM note that correlation between reported returns on hedge funds in consecutive months (i.e., the first-order serial correlation, or autocorrelation, of the reported returns) is much higher than is commonly found in liquid equity or bond returns. They systematically examine numerous possible sources of serial correlation in hedge fund returns, and show that market inefficiencies, time-varying expected returns, time-varying leverage, and incentive fees with high water marks can all generate serial correlation in observed fund returns. However none formance. Another strand of literature focuses more on the risk and return characteristics in specific hedge fund strategies. For example, Mitchell and Pulvino (2001) study the "risk-arbitrage" strategy; Fung and Hsieh (2001) focus on the "trend following" strategy and Agarwal and Naik (2004) study a number of equity-oriented strategies. 
of these sources can generate the magnitude of serial correlation found in the data. They conclude that the observed serial correlation must be the result of exposure to illiquid assets, which can lead to non-synchronicity problems in valuing the assets in the portfolio, inadvertent smoothing due to "marking to model" (as opposed to marking to market), and/or deliberate performance smoothing by managers ${ }^{4}$. Nonsynchronous trading of assets in a portfolio is well known to lead to autocorrelation in portfolio returns, see Shanken (1987) or Lo and MacKinlay (1990) for example. Marking to model will usually lead to serially correlated returns, even for sophisticated pricing models ${ }^{5}$. Further, by influencing how illiquid assets are marked to model hedge fund managers also have the ability to "manage" their reported monthly returns. Lo (2001) argued that given the nature of hedge fund compensation contracts and performance statistics, managers have an incentive to "smooth" their returns by marking their portfolios to less than their actual value in months with large positive returns so as to create a "cushion" for those months with lower returns ${ }^{6}$. This directly results in lower volatility of reported returns and higher Sharpe ratios, see Liew and French (2005). Agarwal et al. (2006) find evidence consistent with hedge fund managers manipulating their reported December returns so as to favorably influence their performance bonuses.

Building on the work of GLM, we exploit the link between autocorrelation in reported returns and exposure to illiquid assets to gain an insight into the time-varying liquidity of hedge fund returns by analyzing the time-varying nature of autocorrelation in hedge fund returns. Our analysis adds a time series dimension to the cross-sectional focus of GLM. GLM measure the illiquidity exposure as averages over the evaluation period, and these averages are taken "unconditionally" without regard to dynamic strategies hedge fund managers usually employ. Unlike traditional fund managers, the strategies of hedge funds are known to be dynamic, with fast turnover, involving both long and short positions, thus hedge funds usually have time-varying exposures to sources of risk. It is thus quite possible that the degree of illiquidity of hedge fund returns is also time-varying. By

\footnotetext{
${ }^{4}$ The connection between (il)liquidity and serial correlation in equity returns has been explored by Campbell, et al. (1993) and Avramov, et al. (2005) for example.

${ }^{5}$ As GLM note, this is related to the fact that the conditional mean of a random variable is always smoother than the random variable itself.

${ }^{6} \mathrm{~A}$ number of studies have examined the impact of serial correlation in returns on estimates of performance or risk exposures, see Dimson (1979), Geltner (1991, 1993), Asness, et al. (2001), Brooks and Kat (2001), Okunev and White (2002), Conner (2003) and Liew and French (2005). Earnings smoothing has also been extensively documented in the studies of accounting management, see Beidlerman (1973), Bannister and Newman (1996), Subramanyam (1996). See also Chandar and Bricker (2002) and Goel and Thakor (2003).
} 
testing whether the degree of serial correlation (or liquidity) varies with certain variables we are able to draw some inferences as to the sources of this illiquidity. For example, how does the degree of illiquidity change with market returns or volatility, or with market-wide liquidity measures? By testing different candidates as the determinants of liquidity, we are able to produce a more complete picture of the sources of hedge fund (il)liquidity. Although the investments and strategies of individual hedge funds are closely-guarded secrets, we are able to indirectly capture the timevarying liquidity of their investments with our approach.

In a related paper, Bollen and Pool (2006) propose a method to distinguish between exposure to illiquid assets and intentional performance smoothing. Their approach is also based on allowing the serial correlation in hedge fund returns to vary through time. Given their tight focus on detecting fraudulent return smoothing, these authors only consider a single factor, namely whether the underlying "true" return on the fund is above or below some benchmark value. The inspiration for this factor stems from the insight that an unscrupulous hedge fund manager may report satisfactory returns more readily than losses, which generates time-varying serial correlation in reported returns. Our specification, described in Section 2, generalizes that of Bollen and Pool to consider a wider variety of factors for time-varying liquidity in hedge fund returns. We also consider all funds in a style category jointly, which greatly increases the power of our method to detect significant liquidity factors.

We follow GLM and assume that reported hedge fund returns are some weighted average of the current and past $q$ lags of true returns on the fund. We allow for time variation in liquidity by allowing the weights on current and lagged true returns to vary over time: a greater weight on the current true return means that more of the true return is reflected in the reported return, consistent with greater liquidity. Conversely, a lower weight on the current true return implies lower liquidity and higher smoothing. The weights are specified as simple functions of a collection of natural candidate variables for a study of liquidity: stock market returns, volatility and liquidity (as proxied by the factor of Pástor and Stambaugh, 2003), bond market returns, volatility and liquidity (as proxied by bid-ask spreads on Treasury bonds), as well as other factors such as a calendar dummy variable and a variable that tracks net flows into the fund. We estimate our model using monthly hedge fund returns from 1993 to 2004 from the CISDM database, and we find significant evidence of time variation in the liquidity of hedge fund returns for seven of the eight hedge fund styles considered. This is true whether we use a model with factors that are measured 
contemporaneously to fund returns, or a model where the factors are all lagged by one month. Somewhat surprisingly, our model using lagged factors, which may be used to predict future hedge fund liquidity, performs approximately as well as the model using contemporaneous factors. In a set of robustness checks, we show that our results hold for both live and "dead" funds, for funds that are open to new money or closed, and for audited versus non-audited funds.

For equity-based hedge fund strategies such as equity market neutral, equity hedge and nonhedge, liquidity decreases when stock market returns are low and bond market returns are high. For hedge fund strategies involving fixed income strategies, such as convertible arbitrage and fixed income arbitrage, liquidity decreases when equity market volatility is high. Fund flow is also a significant determinant of liquidity of these hedge fund strategies, but the direction of the impact of fund flow on hedge fund liquidity varies across strategies. For merger arbitrage and distressed securities, smoothing also increases during the middle of the calendar year. Overall, while we do not find evidence suggesting that the degree of serial correlation in hedge fund returns is directly linked to deliberate performance smoothing for most hedge fund strategies, we do find that for fixed income arbitrage funds, smoothing increases when the "true" return is negative. These results significantly extend the existing literature, and help us to think about the sources of hedge fund (il)liquidity.

The rest of the paper is organized as follows. In Section 2 we discuss our econometric model of time-varying liquidity. We present our set of potential liquidity factors in Section 3, and present our main empirical results in Section 4. In Section 5 we present the results of a simulation study of the finite-sample performance of our model for a variety of scenarios, and show that this performance is satisfactory for sample sizes relevant to our application. Section 6 concludes.

\section{An econometric model of time-varying liquidity}

As discussed in the Introduction, we implement our model of time-varying liquidity in hedge fund returns by exploiting a result of GLM: that hedge fund liquidity is inversely related to the degree of serial correlation in reported fund returns. To quantify the serial correlation in hedge fund returns, GLM assume that the fund $i$ 's reported return, denoted $r_{i t}^{o}$, is a weighted average of its unobserved 
true returns, denoted $r_{i t}$, over the most recent $q+1$ periods:

$$
\begin{aligned}
r_{i t}^{o} & =\theta_{i 0} r_{i t}+\theta_{i 1} r_{i t-1}+\ldots+\theta_{i q} r_{i t-q} \\
\text { where } 1 & =\theta_{i 0}+\theta_{i 1}+\ldots+\theta_{i q}
\end{aligned}
$$

Thus observed returns follow an $\operatorname{MA}(q)$ process. The constraint that the weights sum to one implies that the information driving the fund's performance in period $t$ will eventually be fully reflected in observed returns, and this process could take up to $q+1$ periods from the time the information is generated. The parameter $\theta_{0}$ can be regarded as a proxy for the illiquidity exposure of hedge funds: lower values of $\theta_{0}$ imply that less of the current true return is reflected in the current reported return.

GLM estimate the above model assuming that the weights (i.e. the parameters of the MA process) are constant, and their results may be interpreted as a measure of a hedge fund's average illiquidity over the estimation period. To capture possible time variation of liquidity in hedge fund returns we propose allowing the parameters of the above model $\left(\theta_{0}, \ldots, \theta_{q}\right)$ to vary over time:

$$
r_{i t}^{o}=\theta_{i 0 t} r_{i t}+\theta_{i 1 t} r_{i t-1}+\ldots+\theta_{i q t} r_{i t-q}
$$

We assume that true returns are serially uncorrelated, in order to make the model well-identified, but we do not need to make any assumptions about cross-sectional correlation between the true returns on different funds, and we do not need to assume normality or homoskedasticity. We estimate our model via quasi-maximum likelihood.

In order to make the model empirically feasible given the limited histories available for most hedge funds, we are compelled to make the model as parsimonious as possible. As a step in that direction, we constrain the coefficients on lagged true returns to be a function of a single liquidity "index" variable, denoted $\delta_{i t}$, which completely determines the degree of liquidity of fund $i$ at time $t$. The weights on the true returns are then constrained to decline geometrically towards zero, in a 
similar fashion to an autoregressive process $^{7}$ :

$$
\begin{aligned}
\theta_{i j t} & =\theta_{i 0 t} \cdot \operatorname{sgn}\left(\delta_{i t}\right)\left|\delta_{i t}\right|^{j}, \quad j=1,2, \ldots, q \\
\theta_{i 0 t} & =\frac{1}{\bar{\theta}_{i t}} \\
\text { where } \bar{\theta}_{i t} & =1+\operatorname{sgn}\left(\delta_{i t}\right) \sum_{j=1}^{q}\left|\delta_{i t}\right|^{j}
\end{aligned}
$$

where $\operatorname{sgn}(x)=x /|x|$ for $x \neq 0$, and 0 for $x=0$. By imposing geometric decay on the weights we effectively reduce the number of time-varying parameters to be modelled from $q$ to just one, $\delta_{i t} .{ }^{8}$ Following GLM we set $q=2$, so each reported return is a weighted average of the three most recent true returns. To see how $\delta$ affects the weights on lagged true returns see Figure 1: With $\delta=0$ there is no smoothing: the contemporaneous true return gets weight equal to one, and all lagged returns get weights exactly equal to zero. For $\delta>0$ the weight on the contemporaneous true return decreases, and the weights on lagged returns increase. For $\delta=0.5$ we see that the weight applied to the current true return is only about 0.6, indicating a substantial amount of smoothing. When $\delta<0$ the weight applied to the contemporaneous true return is greater than one, and lagged returns have negative weights. This case corresponds to return 'inflation', whereby the current return is over-reported, and lagged returns are under-reported.

\section{[ INSERT FIGURE 1 ABOUT HERE ]}

We specify the liquidity "index" variable, $\delta_{i t}$, for fund $i$ as a simple function of common liquidity factors, denoted $X_{t}$, and fund-specific liquidity factors, denoted $Z_{i t}$. Examples of the former include variables like stock or bond market volatility, while examples of the latter include net flows into fund

\footnotetext{
${ }^{7}$ We could, of course, parametrize the model as an autoregressive (AR) process rather than a moving average (MA) process. The main drawback of an AR specification is that it implies that any given true return takes an infinitely long time to be fully reflected in the reported returns, a feature that is at odds with the fact that most hedge funds are audited every twelve months. For this reason, we follow GLM and use a MA specification.

${ }^{8}$ We also estimated a fully-flexible MA(q) model on a sub-set of our funds, imposing no time variation in liquidity, and tested whether the geometric decay restriction was binding. The proportion of funds that rejected this restriction was in line with the size of the test, $5 \%$, and so we concluded that this restriction is reasonable for our data.
} 
$i$. We constrain $\delta_{i t}$ to lie inside $(-1,1)$ via the use of the modified logistic function, $\Lambda: \mathbb{R} \rightarrow(-1,1)$

$$
\begin{aligned}
\delta_{i t} & =\Lambda\left(X_{t}^{\prime} \lambda_{i}+Z_{i t}^{\prime} \phi_{i}\right) \\
X_{t}^{\prime} \lambda_{i} & =\beta_{i}+\gamma_{i 1} X_{1 t}+\ldots \gamma_{i M} X_{M t} \\
Z_{i t}^{\prime} \phi_{i} & =\phi_{i 1} Z_{1 t}+\ldots+\phi_{i p} Z_{p t} \\
\Lambda(z) & =\frac{1-e^{-z}}{1+e^{-z}}
\end{aligned}
$$

The model of GLM is obtained as a special case of our flexible model when $\gamma_{i 1}=\ldots=\gamma_{i M}=$ $\phi_{i 1}=\ldots=\phi_{i p}=0$. The model above has a total of $1+M+p$ parameters per hedge fund (not including the unconditional mean and variance parameters). Our initial model has 7 common liquidity factors and 2 fund-specific factors, implying 10 parameters per fund. With the limited time series available on each fund (the median sample size is 46 months), this model is too heavily parameterized. One restriction that greatly enhances the information available for each parameter estimated is to impose that the liquidity factor coefficients are common across funds in a given style category. It would not be reasonable to assume that these parameters are constant across all the funds in our data set, but for funds within a given style this restriction is plausible. Thus we restrict $\gamma_{i k}=\bar{\gamma}_{k} \forall i$ and $\phi_{i l}=\bar{\phi}_{l} \forall i$ for all funds $(i)$ in the same style category, for each factor $(k, l)$. This model thus has "intercepts", $\beta_{i}$, that vary across funds but factor coefficients that are constant across funds in the same style category.

All but one of our liquidity factors are variables that are directly measurable from the data, such as aggregate market returns or net inflows to the fund. Our last factor is specified as the sign of the "true" return on the fund. This factor relies on having an estimate of the true return, which is itself a product of the estimation. Analogous to the estimation of the efficient weight matrix for GMM estimation, we overcome this problem by iteration: We first estimate the model with all desired factors except the sign of the true return. From that model we obtain the estimated true returns, and thus the signs of the estimated true returns. We use this variable as an extra factor in a second estimation of the model. From the second estimation we again obtain the estimated true returns, and we use those in the third estimation, repeating the procedure until the parameters converge. Convergence was usually obtained in three to five iterations ${ }^{9}$. In our "predictive" model

\footnotetext{
${ }^{9}$ We use the sign of the true return, rather than the level of the true return, as the iterative procedure described
} 
for hedge fund liquidity, based on lagged factors, we do not include the sign of the "true" return as a factor, and so no iteration is needed in estimation.

Our use of the sign of the "true return" as a liquidity factor is similar to the Bollen and Pool (2006) model for return smoothing. Their model was specified as a regime-switching AR(1) process, where the $\mathrm{AR}(1)$ coefficient varied according to whether the factor model assumed to be generating the hedge fund returns was above or below some threshold. Our specification is clearly similar in spirit to the Bollen and Pool specification, though we feel that our approach has some key advantages. Firstly, we allow for a wide variety of factors to affect the liquidity of hedge fund returns. This is important because, amongst other reasons, it allows us to control for well-known sources of time-varying liquidity, such as time-varying aggregate market liquidity, before drawing inferences about other possible liquidity factors. Secondly, by focussing just on the sign of the true return, rather than the sign of the fund return in excess of some benchmark value, we avoid having to make any assumptions about the relevant factors for hedge fund returns (though of course we must do so for the factors affecting hedge fund liquidity). This is useful as there is no general consensus in the literature on an appropriate benchmark model for hedge fund returns. Finally, by imposing that the liquidity parameters are the same for all funds in a given style category our estimation procedure dramatically increases our power to detect significant liquidity factors. For seven out of eight styles considered we find evidence of time-varying liquidity that is significant at the $5 \%$ level (discussed in detail in Section 4). Bollen and Pool, on the other hand, detect significant time-varying serial correlation for only about $4 \%$ of their sample, which is approximately equal to the size of their tests $(5 \%)$. This is likely due to their treatment of each fund separately, rather than pooling these funds by style category and thereby gaining more precise parameter estimates from cross-sectional information.

\section{Description of the data and the liquidity factors}

\subsection{The determinants of time-varying liquidity}

As determinants of time-varying hedge fund liquidity, we consider variables that are ex-ante likely to be related to aggregate market liquidity, such as market return, market volatility. A number

above did not always converge when the true return itself was used as a factor. When the sign of the true return was used we did not find any problems attaining convergence. 
of studies (see Pástor and Stambaugh, 2003 and Acharya and Pedersen, 2005 for example) have documented that aggregate liquidity does change over time and liquidity tends to drop when the market is down and volatility is high. In liquid markets, "marking to market" will generally be possible, and the degree of serial correlation in hedge fund returns will be low. When hedge funds' investments are illiquid, market prices are often not available and "fair values" will be determined by using a valuation model ("marking to model"). The calculated "fair value" is a prediction rather than an observation, which induces smoothing even if done as accurately as possible. Moreover, as GLM suggest, intentional performance smoothing is easier when investments are illiquid because of the subjective decisions that have to be made when estimating the "fair value" of an investment. Hence, we also consider variables which are directly related to intentional performance smoothing, such as the time until the next fund audit for example.

Market return: Asness et al. (2001) examine the relationship between hedge fund returns and lagged market returns separately for up and down markets. They find that coefficients on lagged negative market returns are larger than coefficients on lagged positive market returns, suggesting that more smoothing occurs when market returns are low. This could mean that fund managers deliberately smooth returns during market downturns, to reduce the reported losses, but do not smooth during market upturns. On the other hand, the results of Asness et al. may be a consequence of their choice of a single factor: hedge fund returns often display option-like properties, as shown by Fung and Hsieh (1997) for example, and apparent asymmetric factor exposures can occur when asset returns are more or less option-like than the chosen factors, see Jagannathan and Korajczyk (1986). Another explanation, unrelated to intentional smoothing, is that aggregate market liquidity generally decreases during market downturns ${ }^{10}$, making it harder for managers to mark-to-market, thus inducing greater smoothing in downturns than upturns. We will include proxies directly aimed at controlling for aggregate market liquidity, see below, and thus we isolate the impact of market returns on hedge fund liquidity separately from aggregate market liquidity.

We use the return on the S\&P 500 index as the proxy for equity market returns and the return of Lehman Brothers aggregate bond index return as the proxy for bond market returns. The Lehman Brothers index covers government securities, mortgage-backed securities, asset-backed securities and corporate securities to simulate the universe of bonds in the market. The maturity of the

\footnotetext{
${ }^{10}$ See Chordia, et al. (2005) for example. Brunnermeier and Pedersen (2006) provide one theoretical explanation as to why liquidity may "dry up" more often when markets decline.
} 
bonds in the index are all greater than one year.

Market volatility: The well-known positive relation between volatility and volume suggests that in more volatile markets we expect to see more assets being marked to market, rather than marked to model, and thus less smoothing. However, when volatility is high, liquidity is usually low, see Pástor and Stambaugh (2003) and Chordia, et al. (2005) for example. Therefore, high market volatility may lead to less market-wide liquidity, and thus more smoothing in hedge fund returns. As proxies for market volatility, we follow French, Schwert and Stambaugh (1987) and estimate monthly stock and bond market volatility as

$$
\sigma_{t}^{2}=\sum_{i=1}^{N_{t}} r_{i t}^{2}+2 \sum_{i=1}^{N_{t}-1} r_{i t} r_{i+1, t}
$$

where $r_{i t}$ is the daily return on the S\&P 500 or Lehman Brothers bond index on day $i$ in month $t$, and $N_{t}$ is the number of trading days in month $t$.

Market-wide liquidity: The markets in which hedge funds trade also go through periods of high and low liquidity (see footnote 2 for references). Fluctuations in aggregate market liquidity will almost mechanically induce time-varying liquidity in hedge fund returns. Further, periods of low market liquidity correspond to periods when managers can exercise greater discretion in markingto-model, thus perhaps inducing even larger fluctuations in liquidity than in the underlying markets. Both of these observations imply that it is important to control for market-wide liquidity before attempting to infer a relation between hedge fund liquidity and other factors.

Our stock market liquidity measure is the Pástor and Stambaugh (2003) liquidity index from CRSP database. Their monthly measure of aggregate stock market liquidity is a cross-sectional average of individual stock liquidity measures estimated using daily data, which is based on the principle that lower liquidity corresponds to greater volume-related return reversals. The rationale behind this measure is consistent with the model and empirical evidence presented by Campbell, et al. (1993); see also Avramov, et al. (2005). These authors find that returns accompanied by high volume tend to be reversed more strongly, and they explain how this result is consistent with a model in which some investors are compensated for accommodating the liquidity demands of others.

Fleming (2003) reports that the quoted spread is the best measure for monitoring Treasury bond liquidity, and Goldreich, et al. (2005) suggest that quoted spreads are a better measure of liquidity risk in bond market than effective spreads. We follow these papers estimate bond market 
liquidity using quoted bid and ask prices available from the CRSP Treasury Quotes file. This measure is also used by Goyenko (2005).

Fund flows: Fund flows directly affect the hedge fund managers' income because managerial fees are dependent on the size of the fund. Flows, of course, also impact the hedge fund manager's ability to take on positions: capital out-flows force the fund manager to liquidate his positions, thus leading to more marking to market and less smoothing of returns. On the other hand, if a fund manager expects more fund outflows following poor past performance, then in order to reduce outflows he may be more inclined to smooth reported returns.

We compute the percentage net fund flow in month $t$ as the difference between the growth in the total net asset value of the fund and the reported return on the fund. In our first model, we use a forward-looking three month moving average of fund flow as our proxy for fund flows since the date of an out-flow will be known in advance due to redemption notification rules, whereas an in-flow to a fund may or may not be anticipated. In our "predictive" model for hedge fund liquidity we simply use the net fund flow for the previous month.

The sign of "true" return: When "true" returns are positive, part of the gains/losses earned in a given month may not be reported so as to off-set future losses/gains, thus smoothing increases. The SEC (2004) emphasized that valuation problems often arise "when hedge fund advisers overstate assets in order to cover trading losses." On the other hand, it is also possible that low/negative returns on the fund lead to more redemptions, which induces unwinding of positions, enabling marking-to-market, which improves liquidity.

The time until the next fund audit/calendar effects: If hedge fund auditors provide independent confirmation of annual returns, then any intentional smoothing that takes place during the financial year must be "unwound" by the year-end. If hedge fund managers were intentionally smoothing their reported returns, then it would be easiest to do so in the months furthest from an audit date. Unfortunately, the dates of fund audits is not generally publicly available, although Liang (2003) reports that hedge funds are usually audited in December, and Agarwal, et al. (2006) note that bonuses are paid in December ${ }^{11}$. Thus our measure of the time until the next fund

\footnotetext{
${ }^{11}$ Herzberg and Mozes (2003) and Agarwal, et al. (2006) find that hedge fund returns, as opposed to serial correlation in these returns, are not equally distributed across calendar months: on average hedge funds report returns in December that are much larger than other months during the year. Agarwal, et al. (2006) argue that this is because fund managers engage in managing their returns towards the end of the year in order to earn greater
} 
audit is a general "calendar effect" variable, and any seasonal pattern in hedge fund liquidity could also come from a seasonal pattern in aggregate market liquidity. A significant such pattern in U.S. equities is reported by Chordia, et al. (2005) and Hong and Yu (2005). To capture seasonal pattern in hedge fund liquidity, we define the time dummy equal to zero from April to September, one in the rest of the months of the year.

\subsection{Description of the hedge fund returns data}

We use monthly returns and accompanying information on both live and "dead" individual hedge funds from January 1993 to August 2004 from the CISDM database. This database provides monthly observations of returns, total net assets, and net asset values, and a fund information file, containing fund name, strategy type, management fees, and other supplementary details. We analyze 8 fund strategies, namely Merger Arbitrage, Distressed Securities, Equity Hedge, Equity Nonhedge, Market Neutral, Fixed Income Arbitrage, Convertible Arbitrage, Global Macro. Due to the data-intensive nature of the research question, we only study funds with at least 48 months of observations, which leaves us with a total of 609 individual hedge funds. Our use of quasi-maximum likelihood estimation means that our unbalanced panel of hedge fund returns is manageable ${ }^{12}$.

In Table 1 we provide summary statistics on the hedge fund returns over our sample period. For each strategy, the table lists the number of funds and means and standard deviations of basic summary statistics and the smoothing profiles estimated using the GLM MA(2) smoothing process. Consistent with GLM, merger arbitrage, distressed securities, convertible arbitrage and fixed income have relatively high average serial correlations and the estimated smoothing parameter $\hat{\theta}_{0}$ is low on average. Market neutral, equity hedge, equity nonhedge, global macro funds which mainly invest in liquid assets exhibit low serial correlation and $\hat{\theta}_{0}$ is relatively close to unity. Panel A in Table 2 contains summary statistics of our liquidity factors over the sample period. Panel B in Table 2 incentive fees.

${ }^{12}$ Specifically, we estimate the parameters of our time-varying liquidity model for all hedge funds in a given style simultaneously, making the assumption that the "true" returns on each of these funds are cross-sectionally independent. Imposing this incorrect assumption reduces the asymptotic efficiency of the estimator but does not affect consistency. Implementing the fully-efficient estimator requires estimating the correlation matrix of the true returns, which is difficult due to the short time series of data available and is especially difficult due to missing observations. In unreported simulation results we found that estimating the correlation matrix lead to poor finite-sample properties for the sample sizes we have for this study. 
reports pair-wise correlation among the various determinants, and shows that none have excessively high correlation.

\section{[ INSERT TABLES 1 AND 2 ABOUT HERE ]}

\section{Empirical evidence of time-varying hedge fund liquidity}

We present our estimation results in two formats. The first set of results, in Table 3, includes all of the factors discussed in the previous section. The results in this table allow us to examine the impact of a given factor, controlling for the influence of other factors that are possibly relevant for hedge fund liquidity. The cost of including these extra variables is the generally decreased significance of any given individual factor. However, the fact that our model controls for the influence of other relevant variables is an important advantage of our approach.

In Table 4 we report the model resulting from a general-to-simple specification search, where we started with the most general model, and then dropped the factor with the lowest t-statistic and re-estimated the reduced model. We continued eliminating variables, one at a time, until all the factors left in the model were significant at $10 \%$ level $^{13}$. By excluding variables which are not statistically significant we parsimoniously extract factors that are significant determinants the liquidity in hedge fund returns ${ }^{14}$. All standard errors reported in this paper are Newey-West (1987) robust standard errors.

Our initial model imposed that the coefficients on the liquidity factors were common across funds in the same style category, but allowed the "intercepts" ( $\beta_{i}$ in equation 5$)$, or unconditional levels of serial correlation, to vary across each fund in a given style. We tested the additional restriction that the intercept parameters were equal across funds in the same style category and found that this restriction was not rejected for any of the styles we consider. Thus the results we report are from the simplified model with the intercepts imposed to be constant across funds in the same style category.

\footnotetext{
${ }^{13}$ Some detailed discussion of the general to simple model selection procedure can be found in Hendry and Richard (1982, 1983) and Hoover and Perez (1999).

${ }^{14}$ Interestingly, the parameter estimates and t-statistics in the reduced model are not very different from those in the most general model except for equity nonhedge funds, where some insignificant factors in the general model turn out to be significant in the reduced model.
} 
Before discussing the results for particular hedge fund styles, let us firstly describe the results in general. Tables 3 and 4 reveal quite clearly that stock market returns and volatility are important determinants of hedge fund liquidity. The influence of these factors is not merely due to them proxying for market liquidity, since the models reported in Table 3 include controls for stock and bond market liquidity. For five out of the eight styles considered we find stock market returns or volatility to be significant determinants of hedge fund liquidity. The return on the bond index is also an important variable, being significant for three styles. Somewhat surprisingly, the stock market liquidity proxy is not significant for any style (in the general model; it is significant in one of the reduced models) and the bond market liquidity proxy is only significant for one style. This suggests that while these proxies track liquidity in the stock or bond markets well, they are not as good at tracking time-varying liquidity in hedge fund returns. The only remaining variable that was often significant across styles is the fund flows variable: this variable was significant in four out of the eight styles. Interestingly, the sign of this variable was not consistent across styles: for Merger and Convertible Arbitrage styles the sign was negative, indicating that net in-flows lead to higher liquidity, whereas for the Fixed Income and Global Macro styles the sign was positive, indicating that net out-flows lead to higher liquidity.

\section{[INSERT TABLES 3 AND 4 ABOUT HERE]}

To glean some further insight from our models, in Figures 2 and 3 we plot the time series of $\hat{\theta}_{0 t}$, estimated from the general model, for each hedge fund style. For comparison purposes, we also plot the Getmansky, Lo and Makarov (2004) estimate of $\hat{\theta}_{0}$ for each style and a $95 \%$ confidence interval for this estimate. These figures clearly show that the liquidity of hedge fund investments varies significantly over time across all fund styles. Consistent with conventional wisdom that the assets of equity-based funds are more liquid, the general level of $\hat{\theta}_{0 t}$ of equity-based styles is nearer to unity than those of non-equity based styles. However, by allowing $\theta_{0}$ to vary through time important variations in liquidity are found even for funds that have an average $\theta_{0}$ (the "GLM $\theta_{0}$ ") that is near unity. For example, the Equity non-hedge style both has an average $\theta_{0}$ very near one, whereas the time-varying estimates show that $\theta_{0}$ for this styles varies from as low as 0.5 (indicating substantial return smoothing) up to as high as 2.5 (indicating return "inflation").

Interestingly, our model detects a large drop in liquidity around September 1998 in all fund styles except Global macro. This period corresponds to the time of the Russian debt crisis and the collapse 
of LTCM, a period widely-thought to have been one of low aggregate liquidity, see Pástor and Stambaugh (2003) and Brunnermeier and Pedersen (2006) for example. Another large downward spike in our measure of liquidity occurs around July 2002, particularly for the Merger arbitrage, Distressed securities and Convertible arbitrage styles. This corresponds roughly to the outbreak of now-infamous accounting scandals (Enron, Arthur Andersen, Adelphia, and WorldCom). In the plots of Merger arbitrage and Distressed securities funds, time-varying $\hat{\theta}_{0 t}$ also exhibits a strong calendar effect, with liquidity falling in the middle of the calendar year and rising around the end of the year.

\section{[INSERT FIGURES 2 AND 3 ABOUT HERE]}

\subsection{Results for individual hedge fund styles}

Determinants of liquidity in market neutral fund returns: Managers of market neutral funds purchase undervalued securities and short sell overvalued securities so as to neutralize the impact of the overall market. This strategy is regarded as a "zero beta" strategy because the whole portfolio is supposed to have no, or at least low, co-movement with the overall market, although Patton (2005) reports some evidence against this. We find just two significant determinants of liquidity in market neutral fund returns: stock market returns and bond market returns. These factors are significant in the general model and are the only two factors that appear in the reduced model. The general model is significant overall, with a joint test of the hypothesis that all factors have coefficients equal to zero being rejected with a p-value of 0.02 . We find that stock market returns are positively related to market neutral hedge fund liquidity even after controlling for market liquidity. This finding is consistent with the results of Asness et al. (2001), who find that coefficients on lagged negative market returns are larger than coefficients on lagged positive market returns, implying greater smoothing during market downturns. This may be due to managers' intentional performance smoothing during market downturns. However we do not find the sign of "true" return is a significant determinant of the degree of liquidity, which would seem a more relevant indicator of intentional performance smoothing. Further, we find that bond returns have a negative influence on hedge fund liquidity, in that high bond market returns lead to lower liquidity, which is hard to reconcile with an intentional performance smoothing explanation.

Determinants of liquidity in equity hedge fund returns: Like equity market neutral 
funds, equity hedge fund investments also combine holdings of long equities with short sales of stocks and/or stock index options. The difference from market neutral funds is equity hedge fund managers do not aim for a zero beta. They usually increase net long exposures in bull markets and decrease net long exposures or even are net short in bear markets. Similar to equity market neutral funds, we find a positive (negative) relation between stock (bond) market return and the degree of liquidity in equity hedge fund returns. The joint significance of time variation in liquidity is again strong, with a p-value of less than 0.01 .

Determinants of liquidity in equity nonhedge fund returns: Equity nonhedge funds are commonly known as "stock-pickers" because these funds are predominately long in equities. The important distinction between equity non-hedge funds and equity hedge funds is equity non-hedge funds do not always have a hedge in place. Similar to equity hedge funds and market neutral, we find that stock market returns are positively related to the liquidity in equity nonhedge fund returns. However, instead of bond return as a significant determinant of liquidity, we find there is a negative relationship between stock market liquidity and the liquidity in equity nonhedge fund returns. This is the only style category in which the aggregate stock market liquidity proxy was significant, and it is only significant in the reduced model; in the aggregate model the coefficient on this variable has a t-statistic of only 1.21. Overall, however, the general model for time-varying liquidity is very significant, with a p-value from a joint test of constant liquidity being less than 0.01 .

Determinants of liquidity in global macro fund returns: Global macro funds aim to profit from changes in macroeconomies, and participate in equities, bonds, currencies and commodities markets. For this style, we found bond market returns to be positively related to the degree of liquidity in global macro fund returns, indicating lower liquidity for these funds when the bond market is falling. The only other significant factor for this style was the fund flow. This factor has a positive coefficient, indicating that net out-flows (meaning the "net fund flow" variable takes a negative value) increase the liquidity of the fund. This finding is consistent with the scenario where out-flows cause the fund to liquidate some of their positions, which enables marking to market and thus greater liquidity. The global macro style is the only category where the general model for time-varying liquidity could not reject the null of constant liquidity; the p-value for this test is 0.15 .

Determinants of liquidity in merger arbitrage fund returns: Contrary to previous four 
strategies, the merger arbitrage strategy usually involves less liquid assets. Merger arbitrage funds take bets in event-driven situations such as mergers, takeovers, corporate restructuring, spin-offs. In the general model we find only one significant factor: net fund flows. The sign of this coefficient is negative, indicating that net out-flows decrease liquidity. This finding is not consistent with the scenario where out-flows cause the fund to liquidate some of their positions, enabling marking to market. Instead, the sign of this coefficient is consistent with the scenario where a hedge fund manager experiencing net fund out-flows increases the degree of intentional performance smoothing, thus decreasing our estimate of liquidity ${ }^{15}$.

Determinants of liquidity in distressed securities fund returns: This type of fund usually focusses on companies which have been, or are expected to be, in financial difficulties. Investments may be made in bonds, stocks, bank debt, corporate debt, trade claims and/or warrants. Distressed securities are often illiquid and it is not always possible to mark them to market. In contrast to our results for market neutral and equity hedge funds, we find that stock market volatility shows a significant negative relation with liquidity, suggesting that when the stock market is volatile the liquidity of these funds is lower. We also find bond market return is positively related to distressed securities fund liquidity, though only in the reduced model.

Determinants of liquidity in convertible arbitrage fund returns: Convertible arbitrage strategies attempt to take advantage of relative pricing discrepancies between the theoretical and market prices of convertible bonds. If a convertible bond appears to be undervalued, then the manager may take a long position in the convertible bond and short the company's equity to reduce the exposure to equity risk. For these funds we again find that higher stock market volatility leads to lower liquidity of these funds' investments. We also find our aggregate bond market liquidity proxy to be significant, and of the expected sign: lower bond market liquidity leads to lower hedge fund liquidity. Finally, we also found that the net fund flows are a significant factor for these funds. The sign of the coefficient is negative, again suggesting that net fund out-flows decrease the

\footnotetext{
${ }^{15}$ In the reduced model we also find that the calendar dummy is significant and positive, indicating that liquidity is significantly lower in the April-September period than the October-March period. This is consistent with the hypothesis that it is easier for hedge fund managers to intentionally "smooth" their reported returns in the months furthest from an audit date, i.e., in the middle of the calendar year. However it is important to note that this variable is not significant in the general model, where we control for many other relevant variables. If aggregate market liquidity is also seasonal, as found by Chordia, et al. (2005) and Hong and Yu (2005), then by omitting it as a control variable we may spuriously find seasonality in hedge fund liquidity.
} 
liquidity of the fund's investments.

Determinants of liquidity in fixed income fund returns: This strategy attempts to exploit mis-pricing among fixed income securities while neutralizing exposure to interest rate risk. The restriction of constant liquidity is most strongly rejected for this style of hedge funds: the test statistic is 53.16, compared with the critical value of 16.92 at the 0.05 level. As in convertible arbitrage funds, we find liquidity is lower when stock market volatility is high. Particular to fixed income arbitrage funds, the sign of "true" return shows a significant positive relation with liquidity. This is consistent with a scenario where the hedge fund manager intentionally smooths negative returns, while more honestly reports positive returns. It is this type of pattern in hedge fund returns that Bollen and Pool (2006) sought to detect as a potential indicator of fraudulent reporting.

Summary of the determinants of time-varying liquidity in hedge fund returns: Overall, we find substantial evidence of time variation in the amount of smoothing in hedge fund returns. For all but one of the eight style categories studied we were able to reject the null of constant liquidity at the 0.05 level. For equity-based hedge fund strategies, such as equity market neutral, equity hedge and non-hedge, which usually invest in liquid securities and exhibit low serial correlation in their returns, liquidity decreases when stock market returns are low and bond market returns are high. For strategies focussed more on fixed income markets, such as convertible arbitrage and fixed income hedge funds, liquidity decreases when equity market volatility is high. Fund flow is also a significant determinant of liquidity of these less liquid hedge fund strategies. Overall, we do not find evidence of deliberate performance smoothing for most hedge fund strategies, but we do find that for fixed income arbitrage funds, smoothing increases when the "true" return is negative.

\subsection{Predicting hedge fund liquidity}

Our results above strongly suggest that the liquidity of hedge fund investments is time-varying, and that this variation can be at least partially captured using contemporaneous values of such factors as equity market returns and volatility, bond market returns and net fund flows. A natural follow-up question to ask is whether we can predict hedge fund liquidity using these factors. We investigate this question by estimating the same model but using one-month lags of our predictor variables ${ }^{16}$. We drop the "true return" factor from this specification, and we use simply the one-

\footnotetext{
${ }^{16}$ This is in the spirit of the "direct" forecasting approach as opposed to the "iterated" approach, which was found by Marcellino, Stock and Watson (2006) to be preferable for forecasting macroeconomic variables.
} 
month lag of net fund flows, rather than a (forward-looking) three-month average of net fund flows. The results of this specification are presented in Table 4.

The results from this predictive model are broadly consistent with the "contemporaneous" model discussed in the previous section. Seven out of eight styles again exhibit significant time variation in liquidity, although it is the Equity non-hedge style that has no significantly predictable liquidity, whereas in the contemporaneous model it was the Global macro style that appeared to have constant liquidity. For the remaining styles the predictability of fund liquidity is strongly significant: for the Market neutral style the p-value on the test for no predictability is 0.01 , while for the remaining styles they are less than 0.001. Thus hedge fund liquidity appears to be both significantly time-varying, and significantly predictable.

Two main features of the results for the predictive model of hedge fund liquidity stand out. Firstly, the one-month lagged return on the S\&P 500 index is a strongly significant factor for predicting hedge fund liquidity for seven out of the eight styles. In all cases, the sign of the coefficient on the S\&P 500 return is negative, implying that falls in the stock market are followed by decreases in fund liquidity. This is the most consistent result of all the factors, including in the contemporaneous factors. The second prominent finding is for the Pástor-Stambaugh equity liquidity index, which is significant for three styles (Distressed securities, Convertible arbitrage, and Fixed income) and has in all three cases a negative sign, indicated that falls in aggregate liquidity predict falls in fund liquidity the following month.

\section{[ INSERT TABLE 5 ABOUT HERE ]}

\subsection{Robustness checks}

In this section we investigate the robustness of the above findings to hedge fund characteristics beyond stated investment styles. We consider sorting funds by whether they were still reporting to the database as at the end of our sample period or not ("live" versus "dead" funds), whether they were accepting new money at the end of our sample period or not ("open" or "closed"), and whether they had been audited by the end of our sample period.

"Live" versus "dead" funds: We consider this split of the funds to determine whether we can reasonably pool "dead" funds with live funds, the latter of course being of primary interest to investors and regulators, to gain more precise parameter estimators. There were 361 funds still 
reporting at the end of our sample period, leaving 248 "dead" funds. We estimated our model on each of these two groups of funds, and report the results in the first two columns of Table 6. For both of these groups of funds we find the bond market return to be the only significant liquidity factor. It has a positive coefficient, as it did for the market neutral, equity hedge and global macro fund styles, presented in Table 3, indicating that higher bond market returns are associated with lower hedge fund liquidity. Furthermore, the factor coefficient estimates for both of these groups of hedge funds are very similar. These results suggest that the time-varying properties of fund liquidity are not substantially different for live and dead funds.

"Open" versus "closed" funds: One might reasonably think that the incentives facing a hedge fund manager who is not accepting new money are different to those facing a manager who is still accepting new money into his/her fund. Most relevant to this study, the incentives to intentionally smooth returns are presumably greater for managers still looking to increase the size of their fund than those who have closed the fund to new money. There were 308 live funds still open to new money at the end of our sample period, 48 funds were closed to new money, while for five funds we had no information on whether they were still accepting new money or not. We excluded these five funds from this analysis. The estimation results are presented in the third and fourth columns of Table 6 . For both of these groups of funds we again find the bond market return to be the only significant liquidity factor: it has a positive coefficient, indicating that higher bond market returns are associated with lower liquidity for both open and closed funds. We also again find that the coefficient estimates are very similar across these two groups of funds, and so we conclude that the liquidity properties of open and closed funds are not substantially different.

Non-audited funds: If the autocorrelation in reported hedge fund returns was primarily due to intentional return smoothing, rather than just a side-effect of investment illiquidity, then one may expect the model results to differ between funds that had been subject to an audit and those that had not. Almost all of the funds in our database were audited: only 20 out of 609 were not. Of these, 13 were live funds and 7 were dead funds. We estimated our model on the non-audited funds, but it was not feasible computationally to estimate the model on all 589 audited funds jointly. Thus we compare the results for the non-audited funds, presented in the final column of Table 6, with those for the live and dead funds presented in the first two columns. None of the factors for the non-audited funds were significant at the $5 \%$ or $10 \%$ level, however the model overall 
had a p-value of 0.06 , and so is significant at the $10 \%$ level. This slightly reduced significance may be attributable to the fact that there are only 20 funds in this category, and so the amount of cross-sectional information available is limited. The individual coefficient estimates are comparable to those for live and dead funds as a whole, and thus we conclude that non-audited funds are not substantially different from the rest of the funds in our database, and need not be excluded from the pooled estimation of the model.

\section{[ INSERT TABLE 6 ABOUT HERE ]}

\section{$5 \quad$ A simulation study}

With the relatively short samples of hedge fund returns available, and the somewhat complicated nature of our model, it is important to verify that the properties of our estimator are satisfactory for realistic sample sizes. We do this via a small simulation study of our model for a range of realistic scenarios. We are primarily concerned with the finite-sample size of the test, that is, the proportion of times a true null hypothesis is rejected. The null hypotheses of interest in our paper relate to the individual and joint significance of factors for the time-varying liquidity of hedge fund investments.

With this in mind, we simulate from a simple model for hedge fund returns where the liquidity is constant, and then estimate our model which allows for time-varying hedge fund liquidity and test for the significance of the factors in the model. Ideally, the proportion of times that a factor is found to be significant should roughly equal the nominal size of the test, which will be set at $5 \%$ throughout. The data generating process for the hedge fund returns and the liquidity "factors" is:

$$
\begin{aligned}
r_{i t}^{o} & =\left(1-\theta_{i 1}-\theta_{i 2}\right) r_{i t}+\theta_{i 1} r_{i, t-1}+\theta_{i 2} r_{i, t-2}, \quad t=1,2, \ldots, T ; i=1,2, \ldots, K \\
{\left[\begin{array}{c}
r_{i t} \\
\mathbf{f}_{t}
\end{array}\right] } & \sim \operatorname{iid} N\left(\left[\begin{array}{c}
\mu_{i} \\
\mathbf{0}
\end{array}\right],\left[\begin{array}{cc}
\sigma_{i}^{2} & \mathbf{0}_{N}^{\prime} \\
\mathbf{0}_{N} & I_{N}
\end{array}\right]\right)
\end{aligned}
$$

where $I_{N}$ is an identity matrix of dimension $N$ and $\mathbf{0}_{N}$ is a $(N \times 1)$ vector of zeros. Thus we assume that the true returns on hedge fund $i, r_{i t}$, are iid $N\left(\mu_{i}, \sigma_{i}^{2}\right)$. The reported returns, $r_{i t}^{o}$, are then generated as a linear combination of the three most recent true returns, following the model of GLM. We specified the values for $\left(\mu_{i}, \sigma_{i}^{2}, \theta_{i 1}, \theta_{i 2}\right)$ from estimates of a MA(2) model on a randomly selected subset of our funds. The liquidity "factors" were set as simple iid standard 
Normal variables. As the factors in this simulation are iid and independent of the true return, the results of this simulation can be used to justify both specifications (contemporaneous and predictive) of our model.

An important empirical feature of our data is the unbalanced nature of our panel of hedge fund returns. By using both live and dead funds in our analysis we are forced to deal with the fact that some funds drop out of our sample before the last period, and many funds were not present in the first period. In order to replicate this feature of the data in our simulation we randomly selected fifty (the largest value of $K$ we considered in the simulation) funds from our sample and recorded the dates of each fund's first and last observation, $t_{i}^{\text {first }}$ and $t_{i}^{\text {last }}$. From these, we computed

$$
\tau_{i}^{\text {first }}=\frac{t_{i}^{\text {first }}}{T}, \quad \tau_{i}^{\text {last }}=\frac{t_{i}^{\text {last }}}{T}
$$

which reflect the proportions of each sample that were missing from the start and end of the sample for fund $i$. These are helpful when considering various values of $T$; if we instead just matched the values of $\left(t_{i}^{\text {first }}, t_{i}^{\text {last }}\right)$ then for large $T$ the impact of missing data would go to zero. To replicate the missing data in our simulation we used these values of $\left(\tau_{i}^{\text {first }}, \tau_{i}^{\text {last }}\right), i=1,2, \ldots, 50$ to determine which observations we should "throw away". In the tables below we report the results both with and without the missing observations imposed on the simulated data.

The key design parameters in this simulation are the sample size, $T$, the number of funds in the category, $K$, and the number of factors, $N$. Our application involved sample sizes of between 48 and 140, style categories containing between 20 and 121 funds, and a set of factors ranging from 2 to 8 . With this in mind, we used the following: $T=75,150,500 ; K=1,10,50 ; N=1,4$, 8. Ideally we would have also ran the simulation for larger values of $K$ but this was not computationally feasible, given that we need to replicate each scenario hundreds of times to get precise estimates of the finite-sample rejection frequencies. Even this small simulation study was quite computationally burdensome ${ }^{17}$.

The largest value of $T$ we consider is much larger than our longest time series, but we include this value as a check on the quality of the asymptotic approximation: if the finite-sample rejection frequencies are substantially different from their nominal levels when $T=500$ then this may indicate a problem with the assumptions underlying the asymptotic theory. Unsurprisingly, we find that

\footnotetext{
${ }^{17}$ This simulation took approximately 2520 hours (over 100 days) on a Pentium $2.8 \mathrm{GHz}$ machine, for 300 replications.
} 
the $T=500$ scenario leads to satisfactory results in almost all cases.

We present the results for two scenarios: one where there were no missing observations and where the sign of the "true" return is not included as a factor, and a scenario where we imposed some missing observations (described above) and included the sign of the "true" return as a factor ${ }^{18}$. We considered the case with and without the "true return" factor as this factor requires an iterative estimation procedure, whereas the other factor coefficients can be estimated as usual via maximum likelihood. It turned out that the coefficient on the "true return" factor was well-estimated using our iterative procedure.

In Table 7 we present the proportion of times that a single factor was found to have a coefficient significant at the $5 \%$ level. Since the true coefficients on all factors in the simulation are zero, these proportions should be approximately equal to $5 \%$. This is generally what we find. The worst results are obtained when only a single fund is included in the panel $(K=1)$, and when the number of factors considered is large $(N=4,8)$. Most importantly for our study, the results for the scenarios with $T=75,150$ with $K=50$ and $N=4,8$ are close to the nominal size of $5 \%$. Thus we can be reasonably confidant that our t-tests have satisfactory finite sample properties.

In Table 8 we present the proportion of times that we could reject the null hypothesis that all factors have coefficients equal to zero. These results are worse than the individual t-test results, particularly when $K=1$ and $N=4,8$. However, the scenarios with $T=75,150$ with $K=50$ and $N=4,8$, which are the most relevant for our study, are reasonably close to the nominal size of $5 \%$. The tendency for this joint test to slightly over-reject the null hypothesis suggests that we should be careful interpreting results where the rejection of the null is "borderline". We rejected the null of constant liquidity for seven of our eight styles, and for six of the eight styles the p-value was less than 0.001. For the market neutral style the p-value was 0.022 , and so these simulation result may indicate that the evidence against constant liquidity is slightly weaker for this style than the asymptotic theory would suggest.

Overall, we conclude from this simulation study that our econometric approach has reasonable properties in finite samples, particularly when the funds are "pooled" together and treated jointly.

\footnotetext{
${ }^{18}$ In unreported results (available from the authors upon request) we also considered the two other cases, involving missing observations but without the "true return" factor, or involving no missing observations and including the "true return" factor. The bulk of the differences between the two cases presented here is attributable to the creation of missing observations; the impact of including the "true return" factor is minimal.
} 
With longer samples $(T=500)$ our simulation results suggest that it is feasible to treat each fund separately, thus allowing greater flexibility in modelling time-varying liquidity, but for the sample sizes currently available $(T=75,150)$ pooling of funds is a simple way of improving the accuracy of the tests.

\section{[ INSERT TABLES 7 AND 8 ABOUT HERE ]}

\section{Concluding remarks}

In this paper we proposed a method to identify and analyze the key determinants of hedge fund liquidity. Our approach does not require information on the actual positions taken by the hedge fund, rather we use only the monthly returns reported by the hedge fund and other easily observed information. We find substantial evidence of time variation in the liquidity of hedge fund returns, and this variation can be predicted with readily available data. Hedge funds in equity-based styles, such as equity market neutral and equity hedge or non-hedge, exhibit decreases in liquidity when stock market returns are low and bond market returns are high. In contrast, hedge funds in fixed income styles, such as convertible arbitrage or fixed income arbitrage, exhibit lower liquidity when equity market volatility is high, and when the fund experiences in-flows or out-flows of funds.

Our methodology and empirical findings on the key determinants of hedge fund liquidity have important implications for investors in and regulators of hedge funds. It is usually very difficult for hedge fund investors to closely monitor liquidity risk of hedge funds, since the risk exposure of hedge funds can change dramatically in response to market conditions. Our methodology provides an alternative means for investors to capture time-varying liquidity of hedge fund investments. It is also useful for regulators to monitor potential market liquidity risk resulting from the opacity of hedge funds' investments. While direct regulation of hedge fund positions would require comprehensive (and sensitive) information, our approach offers a convenient (and less controversial), way to estimate the liquidity of hedge fund investments since only the reported returns on the fund and other currently available data.

The identification of key determinants of hedge fund liquidity also sheds some light on the issue of evaluation of hedge fund assets. The accurate and impartial valuation of hedge fund assets has become an increasingly important issue in the hedge fund industry ${ }^{19}$. Our results indicate that

\footnotetext{
${ }^{19}$ Whether the significant autocorrelation in hedge fund returns is due to hedge funds' systematic illiquidity exposure
} 
especially for some hedge fund strategies involving particularly illiquid assets, such as the fixed income style, a consistent valuation standard or an independent administrator appointed to carry out the valuation may be needed.

Whilst our results shed new light on the factors that are correlated with the liquidity of hedge fund investments, our reduced-form econometric model is not able to definitively separate the possible causes of these observed correlations. For example, equity market returns were found to be an important factor for several of the style categories we considered, and we found that periods of low equity returns correspond to periods of low hedge fund liquidity. One scenario that would generate such a correlation is if funds find it harder to mark to market in falling markets. In that case, falling markets correspond to times when funds rely more heavily on "marking to model", which is revealed as lower liquidity in our approach. Another, less benign, scenario is one where the incentives to intentionally smooth reported returns lead fund managers to indulge in this practice more often in falling markets. Separating these two scenarios requires a theoretical model with careful descriptions of the preferences and incentives faced by the relevant agents: managers, investors, and regulators. Our empirical results will be useful in checking the realism of the predictions from this type of model, but we leave the development such a model to future research.

or managers' intentional performance smoothing is directly related to the question whether the valuations of hedge fund assets are accurate and impartial. The answer to this question is of particular importance to regulators and was the central topic of a speech given by the United Kingdom Financial Service Authority's asset management sector head (Dan Waters) at a conference in March 2006. He noted that "In 2005, valuation related losses in hedge funds were estimated to total $\$ 1.6$ billion. Poor valuation procedures in combination with weak internal controls were in some cases exploited to misrepresent hedge fund valuations and commit fraud." 


\section{References}

[1] Acharya, V. V. and L.H. Pedersen, 2005, Asset pricing with liquidity risk, Journal of Financial Economics, 77(2), 375-410.

[2] Ackermann, C., R. McEnally and D. Ravenscraft, 1999, The Performance of Hedge Funds: Risk, Return, and Incentives, Journal of Finance, 54, 833-874.

[3] Agarwal, V. and N.Y. Naik, 2000, Multi-period Performance Persistence Analysis of Hedge Funds, Journal of Financial and Quantitative Analysis, 35, 327-342.

[4] Agarwal, V. and N.Y. Naik, 2004, Risks and Portfolio Decisions Involving Hedge Funds, Review of Financial Studies, 17, 63-98.

[5] Agarwal, V., N.D. Daniel, and N.Y. Naik, 2003, Flows, Performance, and Managerial Incentives in the Hedge Fund Industry, Working paper, Georgia State University.

[6] Agarwal, V., N.D. Daniel, and N.Y. Naik, 2006, Why is Santa So Kind to Hedge Funds? The December Return Puzzle!, Working paper, Georgia State University.

[7] Aragon, G., 2007, Share Restrictions and Asset Pricing: Evidence from the Hedge Fund Industry, Journal of Financial Economics, 83, 33-58.

[8] Asness, C., R. Krail, and J. Liew, 2001, Do Hedge Funds Hedge? Journal of Portfolio Management, 28, 6-19.

[9] Avramov, D., T. Chordia, and A. Goyal, 2005, Liquidity and Autocorrelations in Individual Stock Returns, Journal of Finance, forthcoming.

[10] Bannister, J.W., and H.A. Newman, 1996, Accrual Usage to Manage Earnings Towards Financial Forecasts, Review of Quantitative Finance and Accounting, 7, 259-78

[11] Beidlerman, C.R., 1973, Income Smoothing: The Role of Management, Accounting Review, $48,635-67$.

[12] Bollen, N.P.B. and V.K. Pool, 2006, Conditional Return Smoothing in the Hedge Fund Industry, Journal of Financial and Quantitative Analysis, forthcoming.

[13] Brooks, C. and H.M. Kat, 2002, The Statistical Properties of Hedge Fund Index Returns and Their Implications for Investors, Journal of Alternative Investments, 5, 26-44.

[14] Brunnermeier, M.K. and L.H. Pedersen, 2005, Predatory Trading, Journal of Finance, 60(4), 1825-1863.

[15] Brunnermeier, M.K. and L.H. Pedersen, 2006, Market Liquidity and Funding Liquidity, mimeo, Princeton University.

[16] Campbell, J., S. J. Grossman, and J. Wang, 1993, Trading Volume and Serial Correlation in Stock Returns, Quarterly Journal of Economics, 108, 905-939.

[17] Chandar, N. and R. Bricker, 2002, Incentives, Discretion, and Asset Valuation in Closed End Mutual Funds, Journal of Accounting Research, 40, 1037-1070. 
[18] Chordia, T., A. Sarkar, and A. Subrahmanyam, 2005, An Empirical Analysis of Stock and Bond Market Liquidity, Review of Financial Studies, 18(1), 85-129.

[19] Conner, A., 2003, The Asset Allocation Effects of Adjusting Alternative Assets for Stale Pricing, Journal of Alternative Investments, 6(3), 42-52.

[20] Dimson, E., 1979, Risk measurement when shares are subject to infrequent trading, Journal of Financial Economics, 7, 197-226.

[21] Edwards, F., and M. Caglayan, 2001, Hedge Fund and Commodity Fund Investments in Bull and Bear Markets, The Journal of Portfolio Management, 27, 97-108.

[22] Fleming, M., 2003, Measuring Treasury Market Liquidity, Federal Reserve Bank of New York Economic Policy Review, 9, 83-108.

[23] French, K.R., G.W. Schwert and R.F. Stambaugh, 1987, Expected stock returns and volatility, Journal of Financial Economics, 19, 3-29.

[24] Fujimoto, A., 2004, Macroeconomic Sources of Systematic Liquidity, mimeo, University of Alberta.

[25] Fung, W. and D.A. Hsieh, 1997, Empirical Characteristics of Dynamic Trading Strategies: The Case of Hedge Funds, Review of Financial Studies, 10, 275-302.

[26] Fung, W. and D.A. Hsieh, 2001, The Risk in Hedge Fund Strategies: Theory and Evidence from Trend Followers, Review of Financial Studies, 14, 313-341.

[27] Fung, W. and D.A. Hsieh, 2002, Asset-based Hedge-fund Style Factors for Hedge Funds, Financial Analysts Journal, 58, 16-27.

[28] Fung, W. and D.A. Hsieh, 2004, Hedge Fund Benchmarks: A Risk Based Approach, Financial Analysts Journal, 60, 65-80.

[29] Geltner, D.,1991, Smoothing in Appraisal-Based Returns, Journal of Real Estate Finance and Economics, 4, 327-345.

[30] Geltner, D.,1993, Estimating Market Values from Appraised Values without an Efficient Market, Journal of Real Estate Research, 8, 325-345

[31] Getmansky, M., A.W. Lo, and I. Makarov, 2004, An econometric model of serial correlation and illiquidity in hedge fund returns, Journal of Financial Economics, 74, 529-609.

[32] Goel, A.M. and A.V. Thakor, 2003, Why do firms smooth earnings?, Journal of Business, 76(1), 151-192.

[33] Goldreich, D., B. Hanke and P. Nath, 2005, The Price of Future Liquidity: Time-Varying Liquidity in the U.S. Treasury Market, Review of Finance, 9, 1-32.

[34] Goyenko, R., 2005, Stock and Bond Pricing with Liquidity Risk, Working paper.

[35] Hendry, D. and J. F. Richard, 1982, On the Formulation of empirical Models in Dynamic Econometrics. Journal of Econometrics, 20, 3-33. 
[36] Hendry, D. and J. F. Richard, 1983, The Econometric Analysis of Economic Time Series, International Statistical Review, 51, 111-163.

[37] Herzberg, M.M. and H.A. Mozes, 2003, The Persistence of Hedge Fund Risk: Evidence and Implications for Investors, Journal of Alternative Management, 6, 22-42.

[38] Hong, H. and J. Yu, 2005, Gone Fishin': Seasonality in Trading Activity and Asset Prices, working paper.

[39] Hoover K.D. and S.J. Perez, 1999, Data Mining Reconsidered: Encompassing and the Generalto-specific Approach to Specification Search, Econometrics Journal, 2(2), 167-191.

[40] Jagannathan, R. and R.A. Korajczyk, 1986, Assessing the Market Timing Performance of Managed Portfolios, Journal of Business, 59, 217-235.

[41] Johnson, T.C., 2006, Dynamic Liquidity in Endowment Economies, Journal of Financial Economics, 80, 531-562.

[42] Liang, B., 1999, On the Performance of Hedge Funds, Financial Analysts Journal, 55, 72-85.

[43] Liang, B., 2000, Hedge Funds: The Living and the Dead, Journal of Financial and Quantitative Analysis, 35, 309-326.

[44] Liang, B., 2001, Hedge Fund Performance: 1990-1999, Financial Analysts Journal, 57, 11-18.

[45] Liang, B., 2003, Hedge Fund Returns: Auditing and Accuracy, Journal of Portfolio Management, 29, 111-122

[46] Liew, J. and C. French, 2005, Quantitative Topics in Hedge Fund Investing , Journal of Portfolio Management, 31, 21-32

[47] Lo, A.W., 2001, Risk Management For Hedge Funds: Introduction and Overview, Financial Analysts Journal, 57, 16-33.

[48] Lo, A.W. and A.C. MacKinlay, 1990, An Econometric Analysis of Nonsynchronous Trading, Journal of Econometrics, 45, 181-212.

[49] Marcellino, M., J.H. Stock and M.W. Watson, 2006, A Comparison of Direct and Iterated Multistep AR Methods for Forecasting Macroeconomic Time Series, Journal of Econometrics, $135,499-526$.

[50] Mitchell, M.,and T. Pulvino, 2001, Characteristics of Risk in Risk Arbitrage, Journal of Finance, 56, 2135-2175.

[51] Newey, W. and K.D. West, 1987, A Simple, Positive, Heteroskedasticity and Autocorrelation Consistent Covariance Matrix. Econometrica, 55, 703-705.

[52] Okunev J. and D. White, 2003, Hedge Fund Risk Factors and Value at Risk of Credit Trading Strategies, Working paper, Principal Global Investors and University of New South Wales.

[53] Pástor, L. and R. Stambaugh, 2003, Liquidity Risk and Expected Stock Returns, Journal of Political Economy, 111, 642-685. 
[54] Patton, A.J., 2005, Are 'Market Neutral' Hedge Funds Really Market Neutral?, Discussion Paper 522, Financial Markets Group, London School of Economics.

[55] Securities and Exchange Commission, 2004, Registration Under the Advisers Act of Certain Hedge Fund Advisers, File No. S7-30-04, United States Securities and Exchange Commission, Washington, D.C.

[56] Shanken, J., 1987, Nonsynchronous Data and the Covariance-factor Structure of Returns, Journal of Finance, 42, 221-232.

[57] Subrahmanyam, K.R., 1996, The Pricing of Discretionary Accruals, Journal of Accounting and Economics, 22, 250-81 


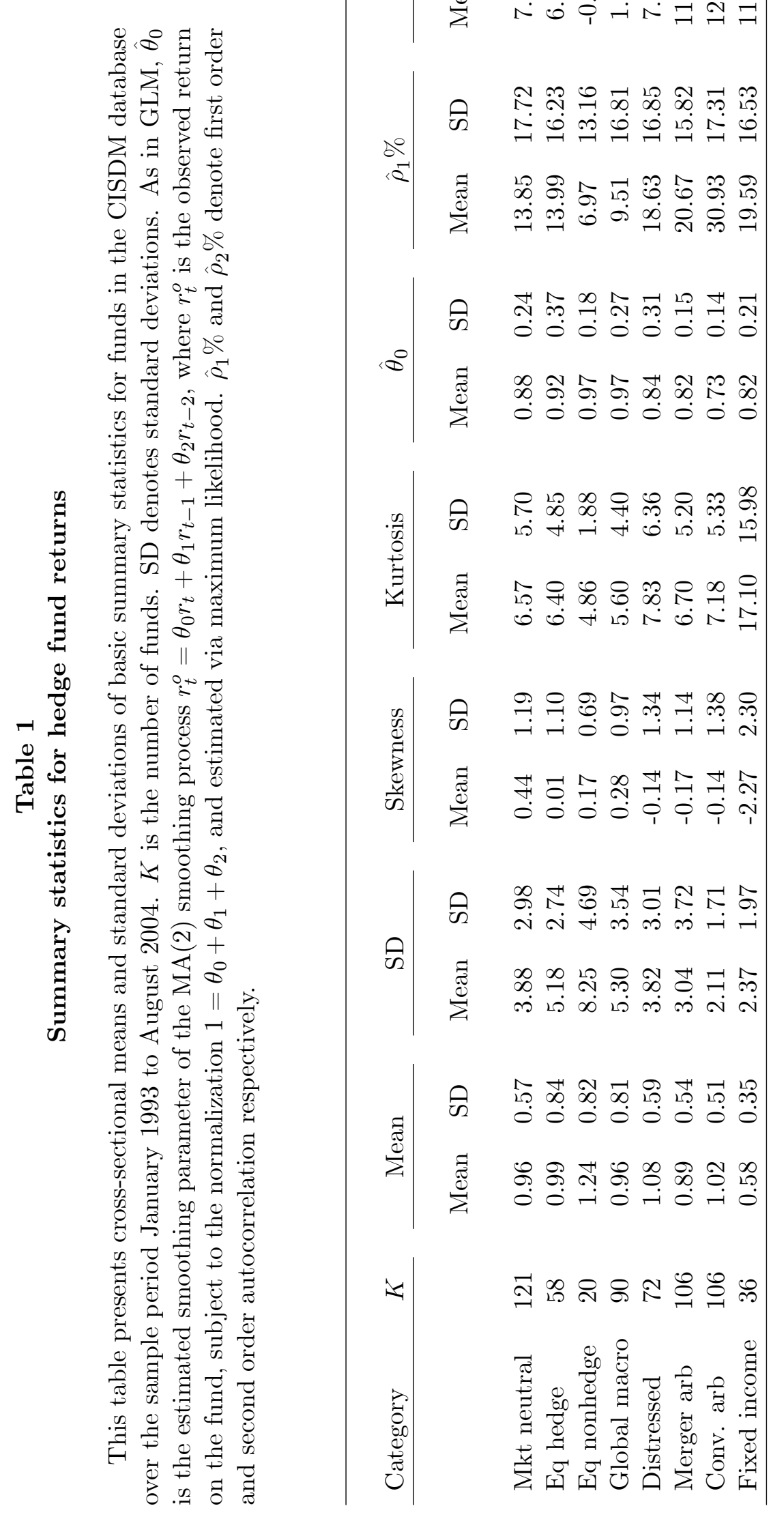




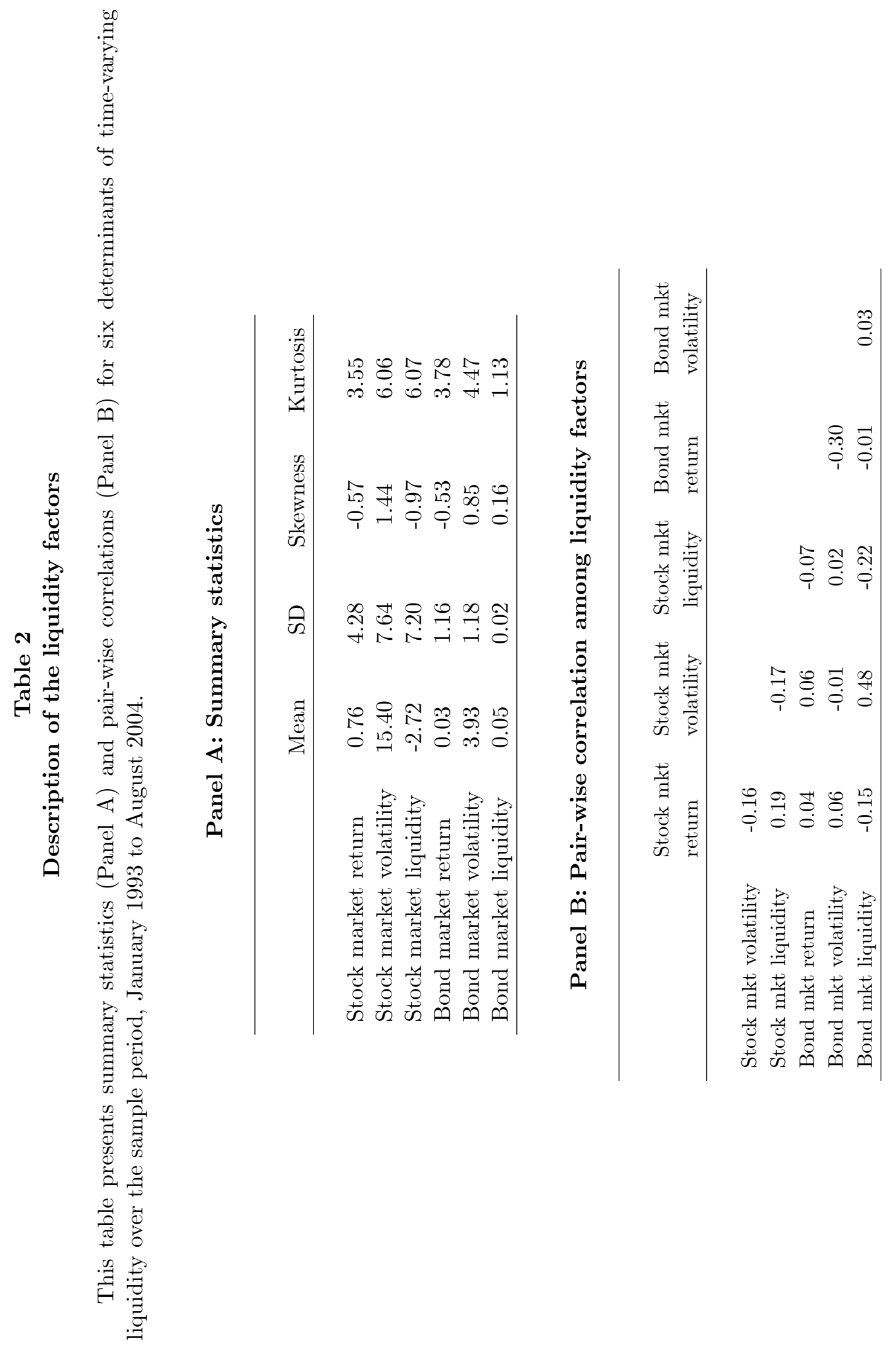




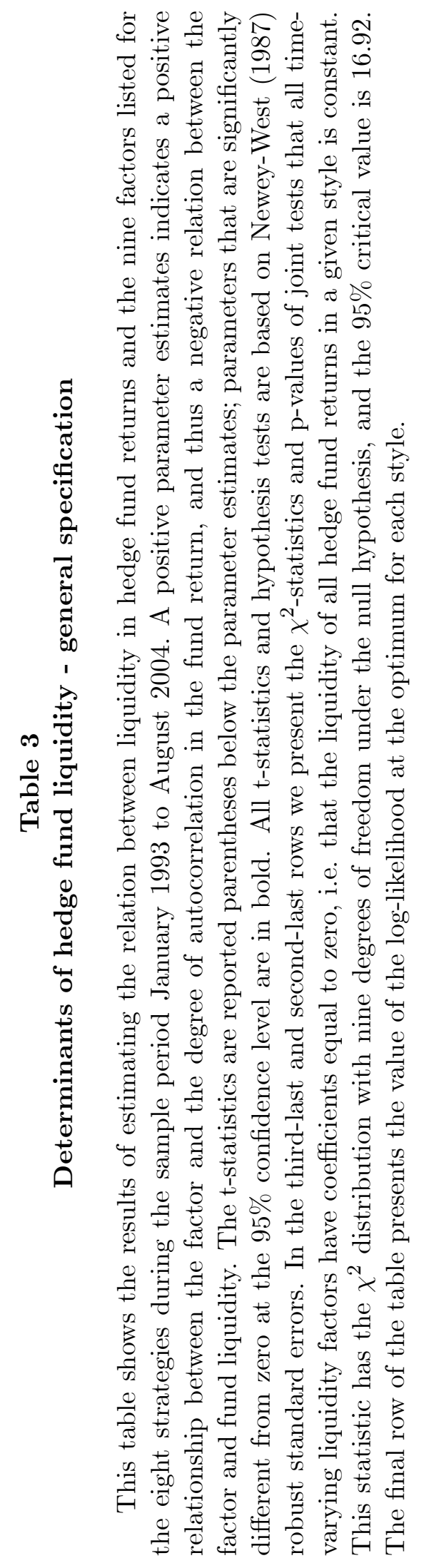




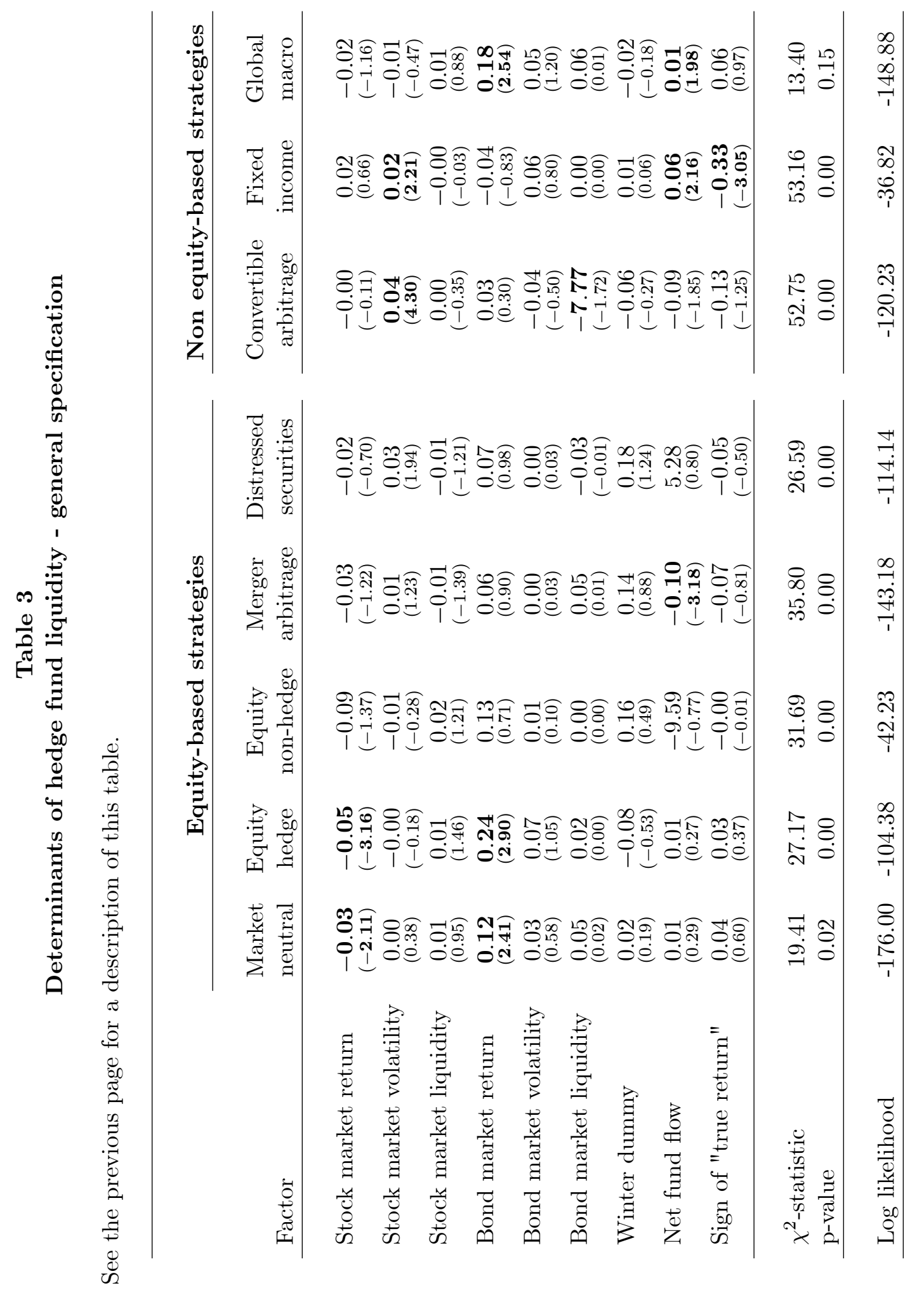




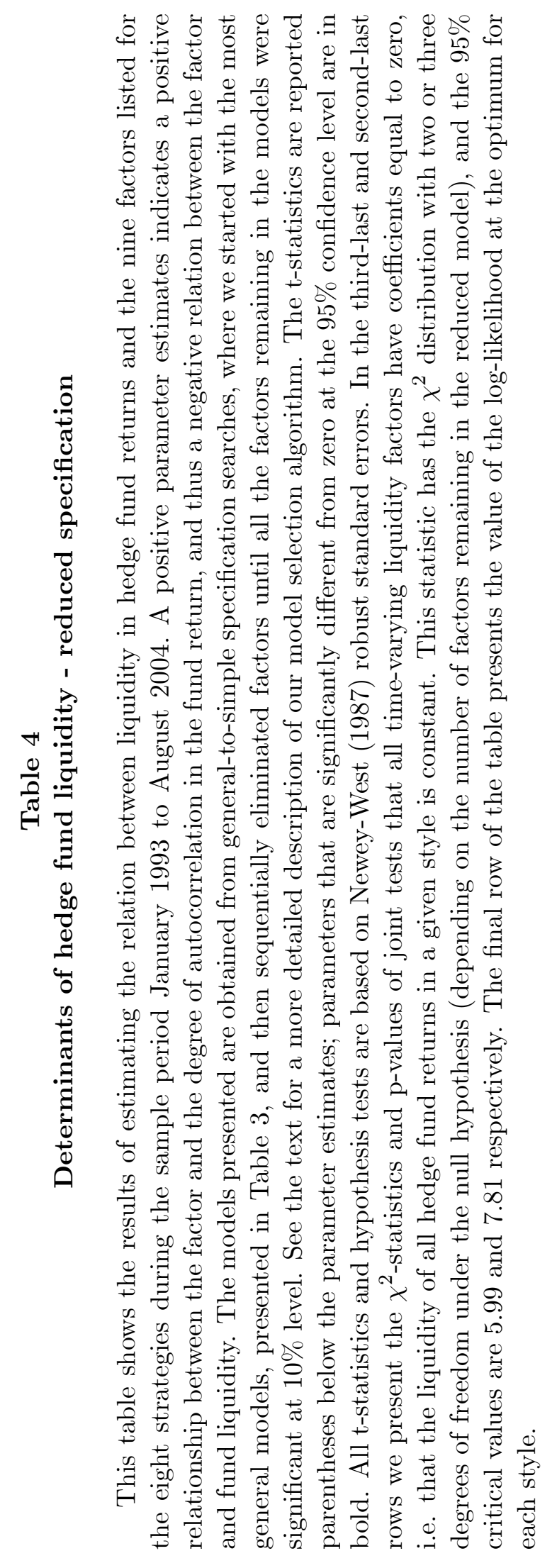




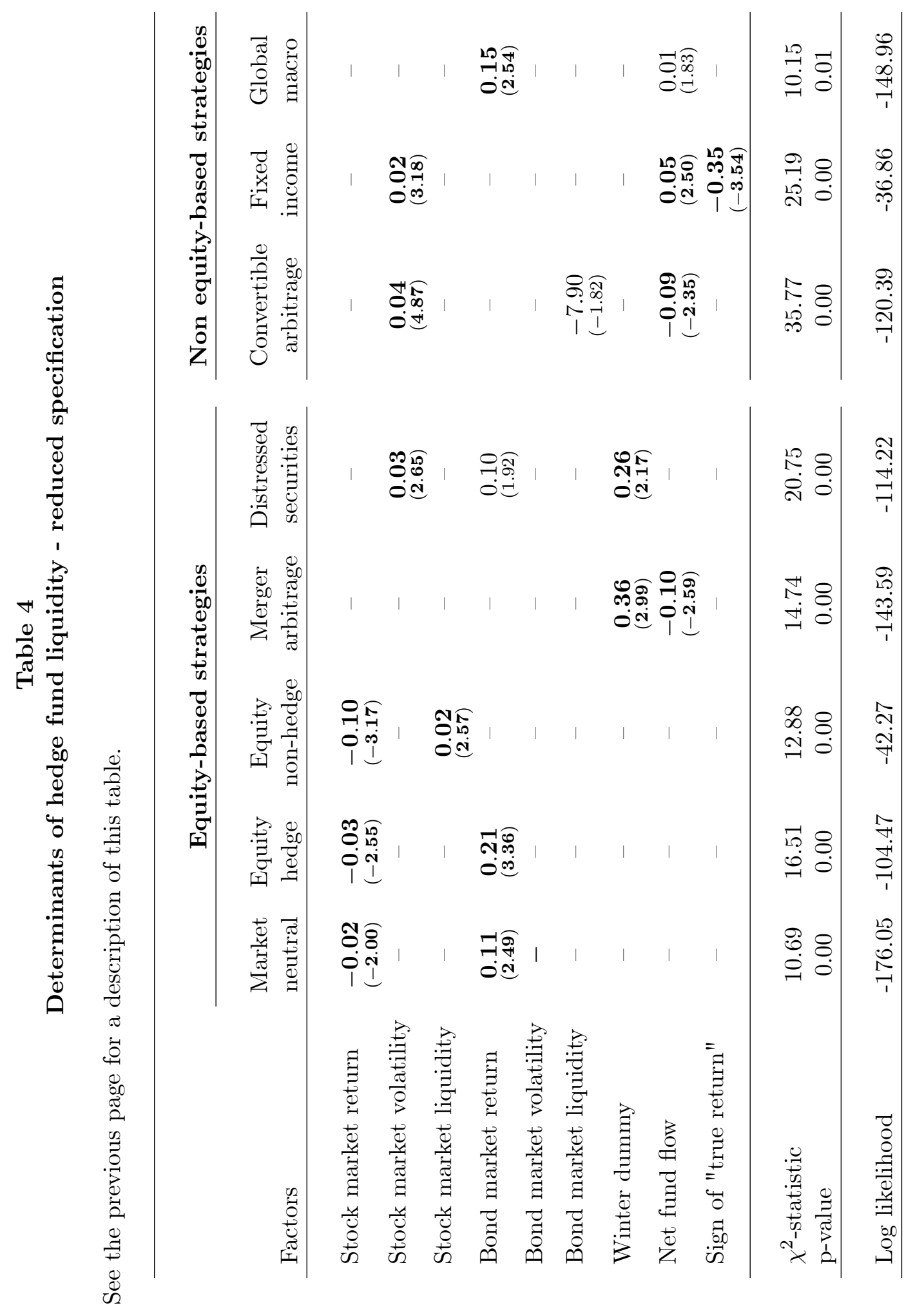




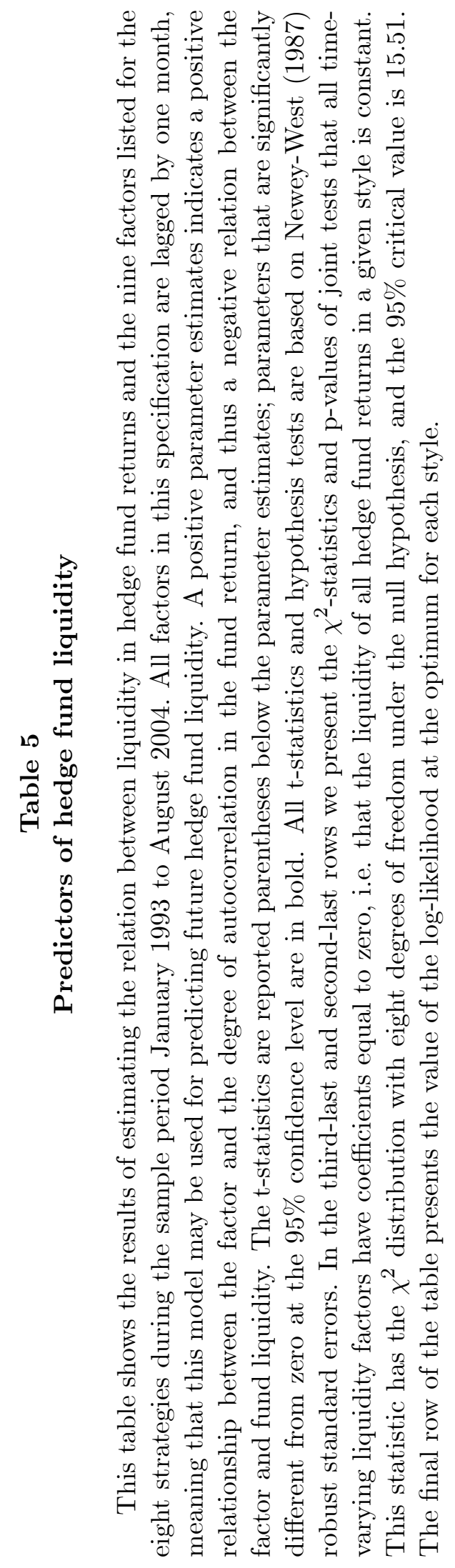




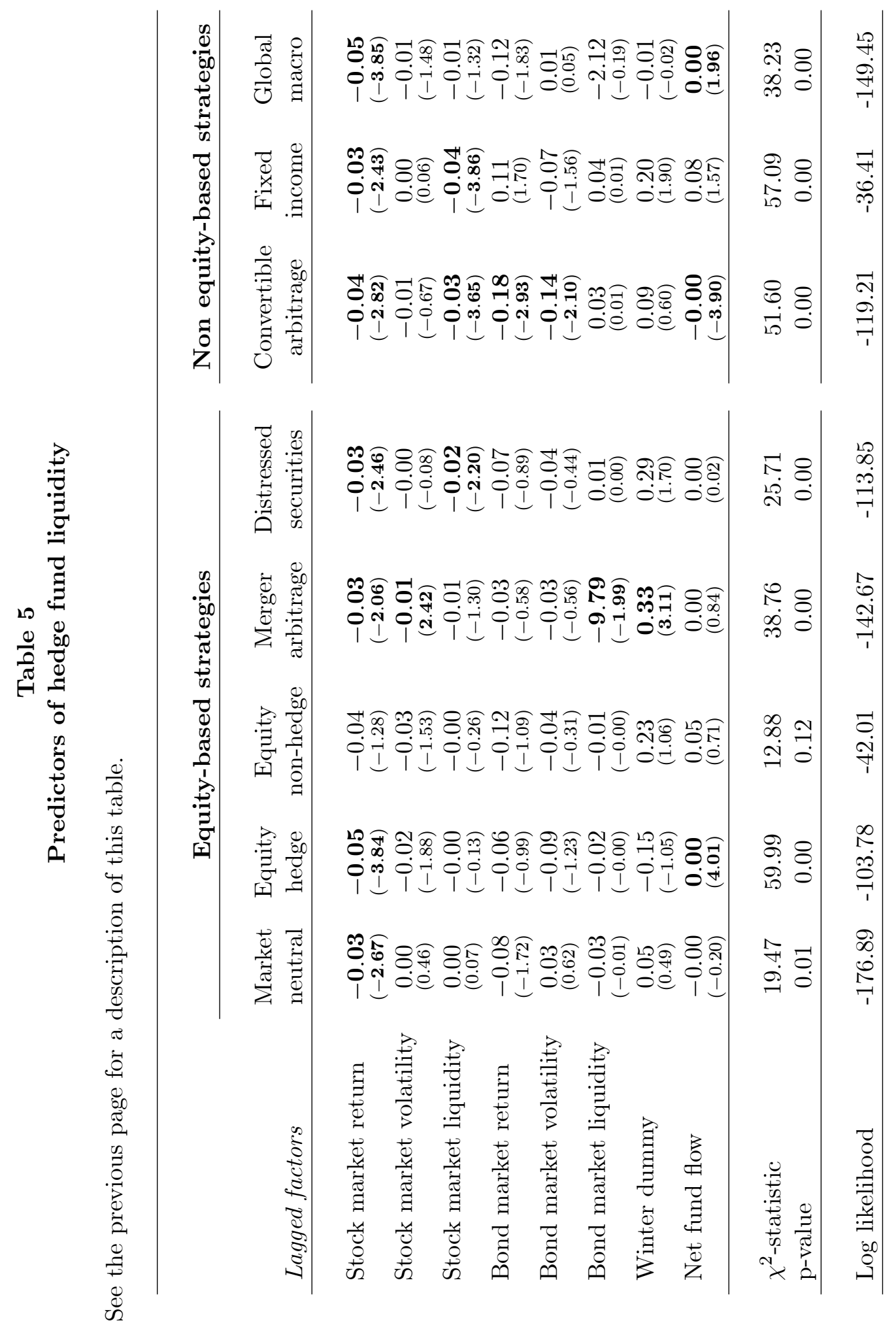




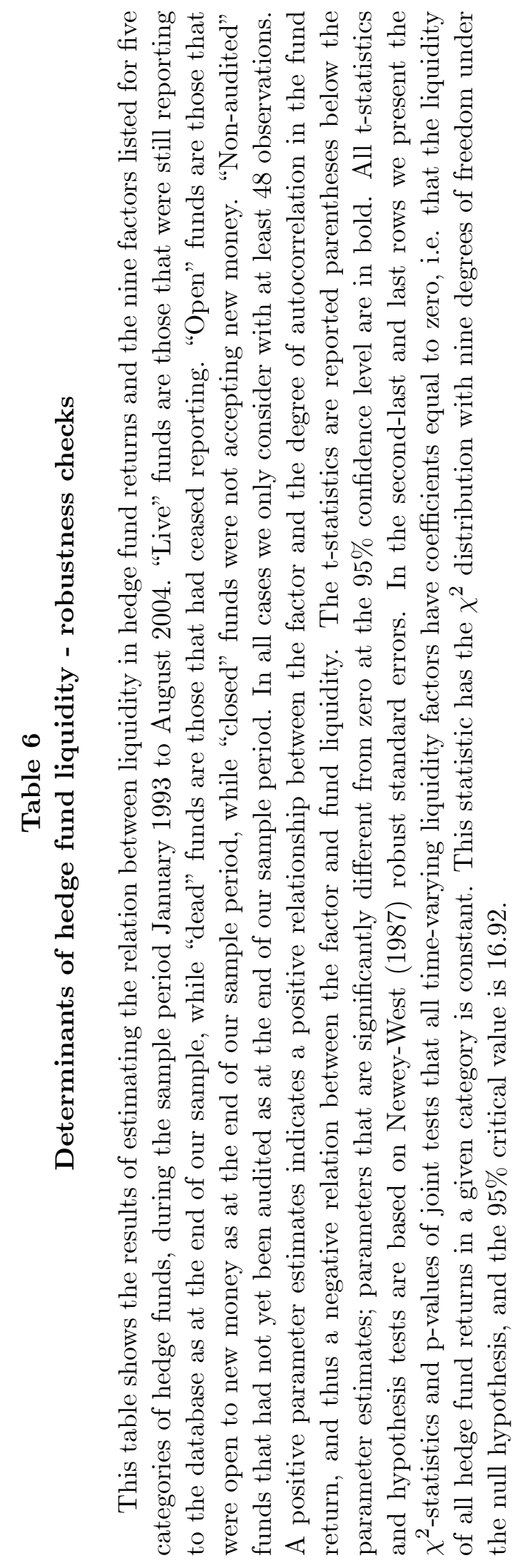




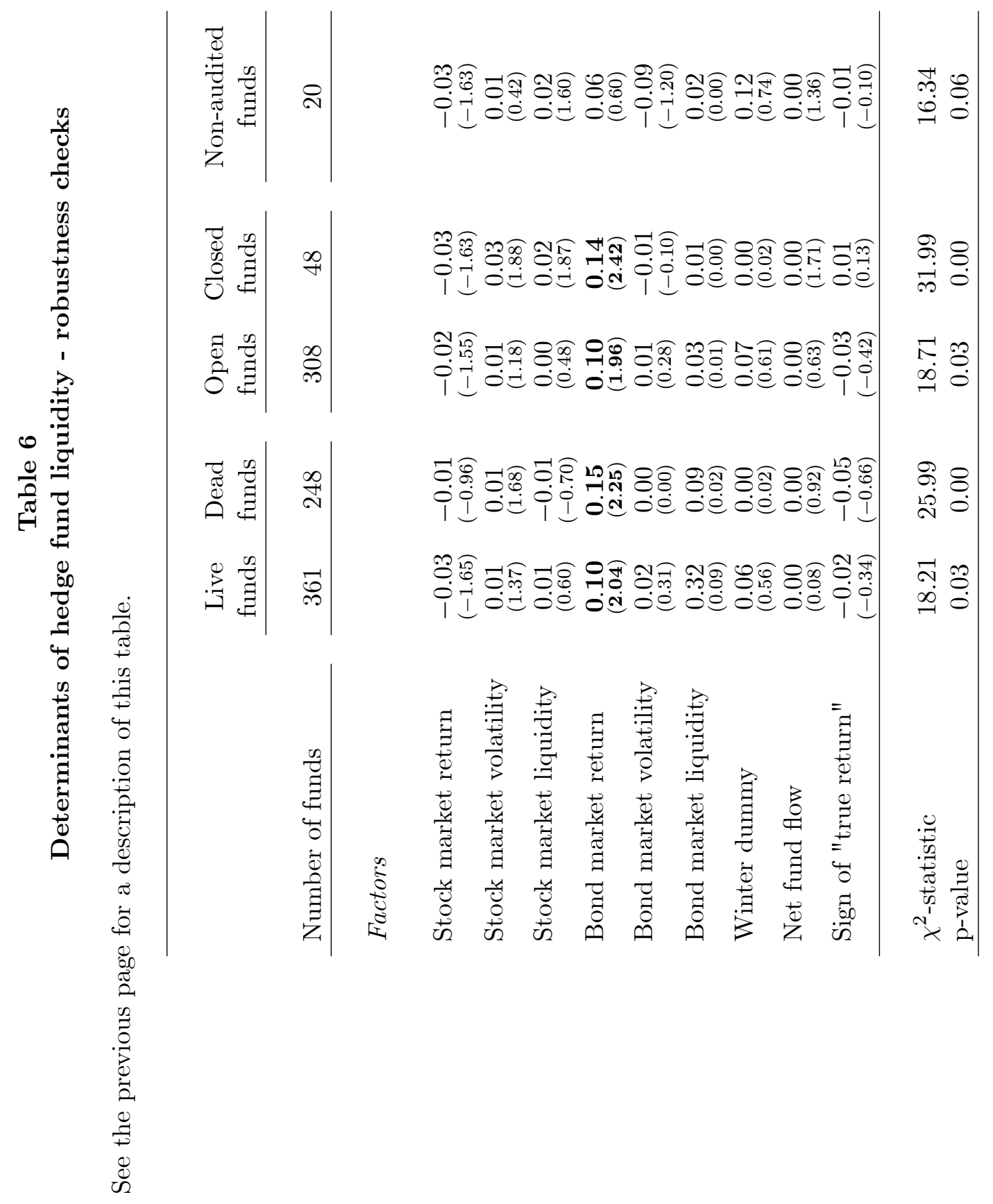




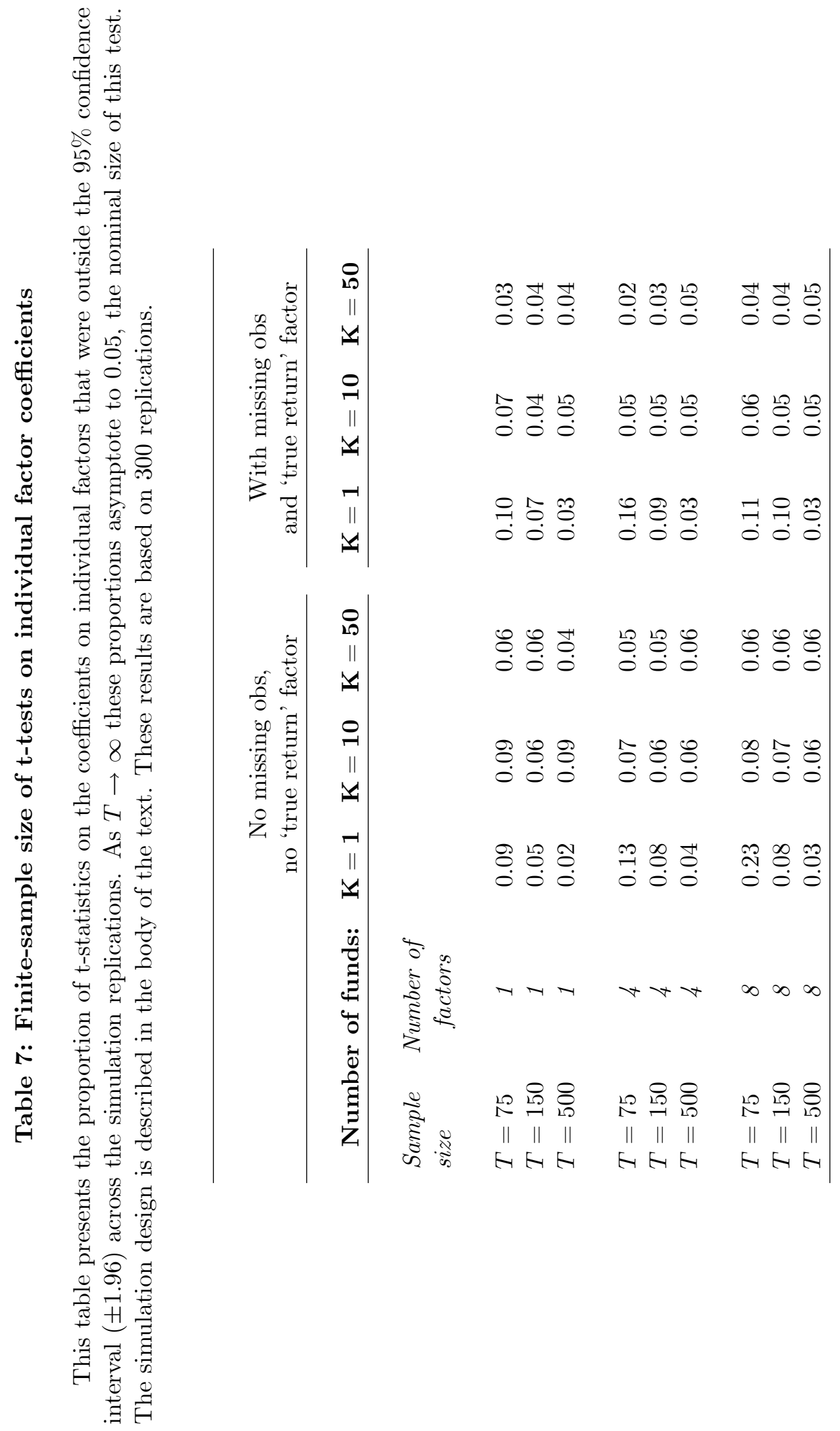




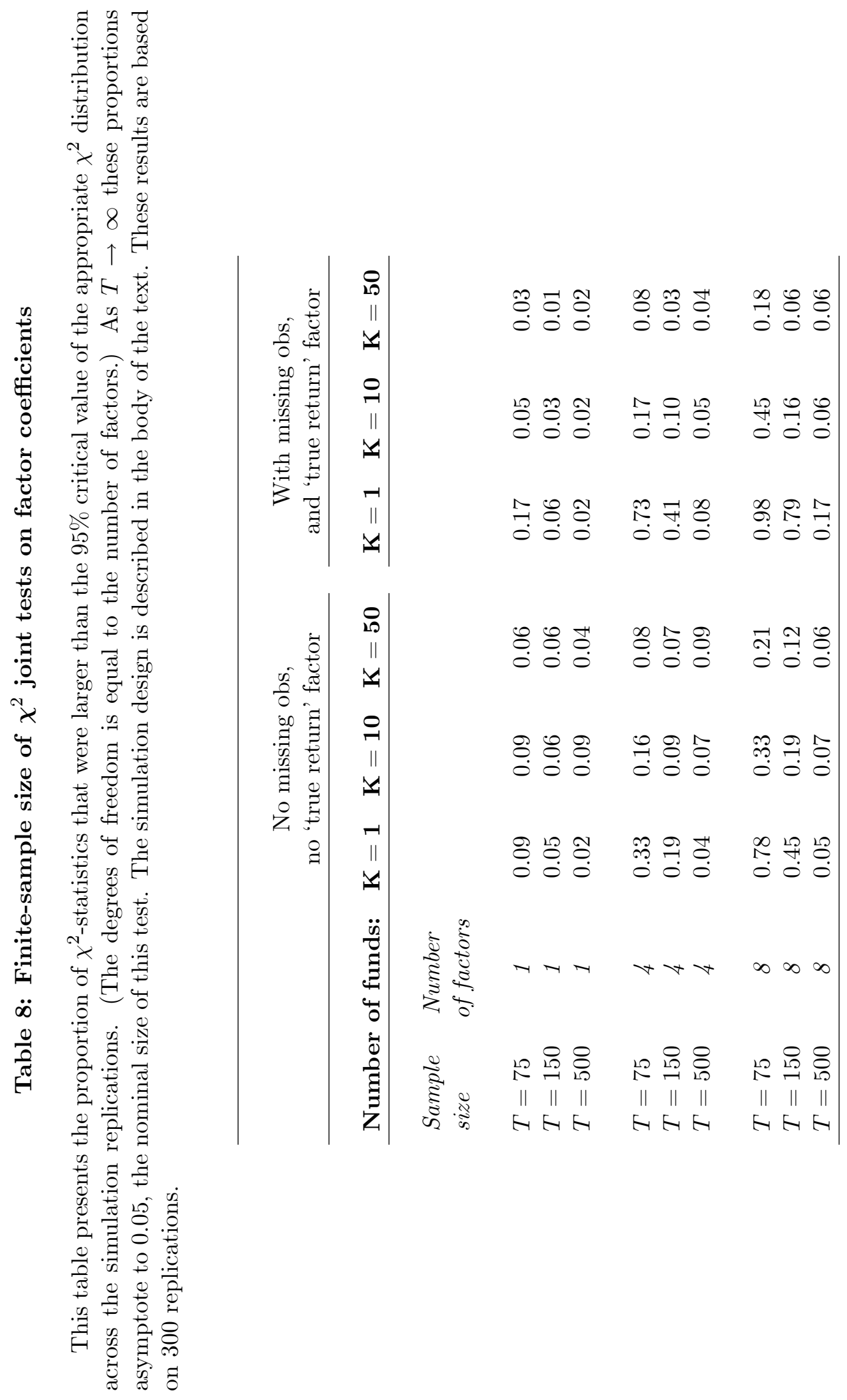




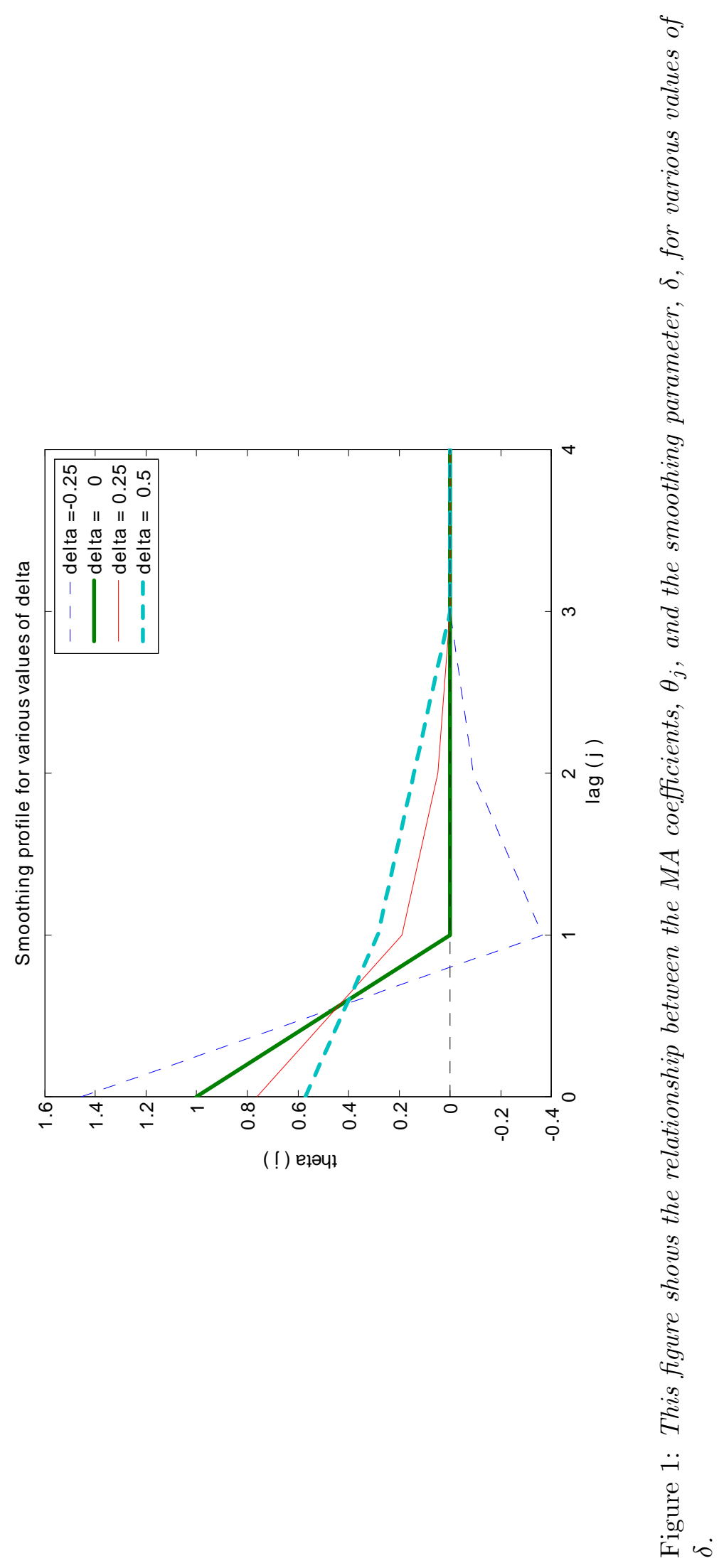



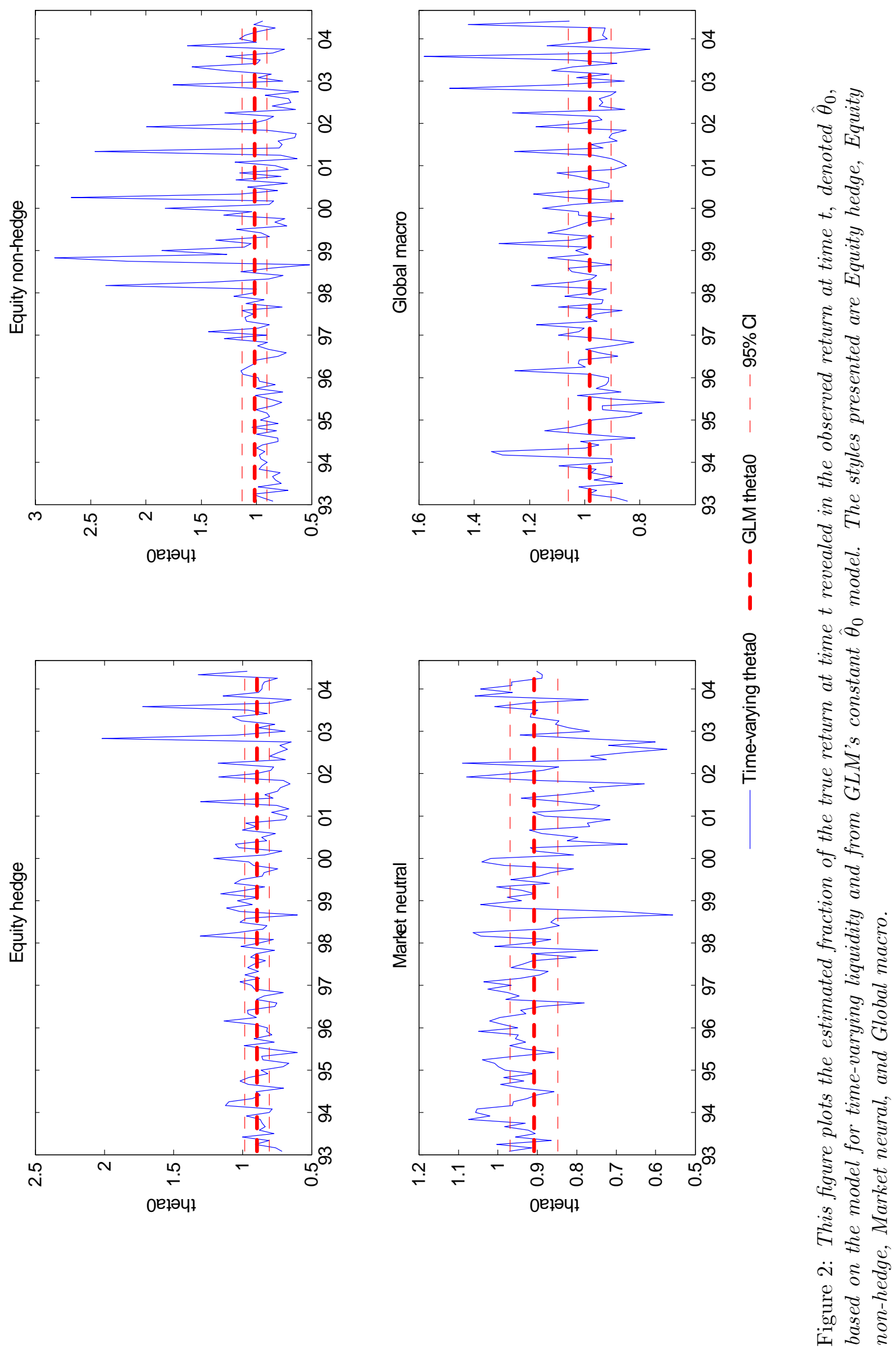

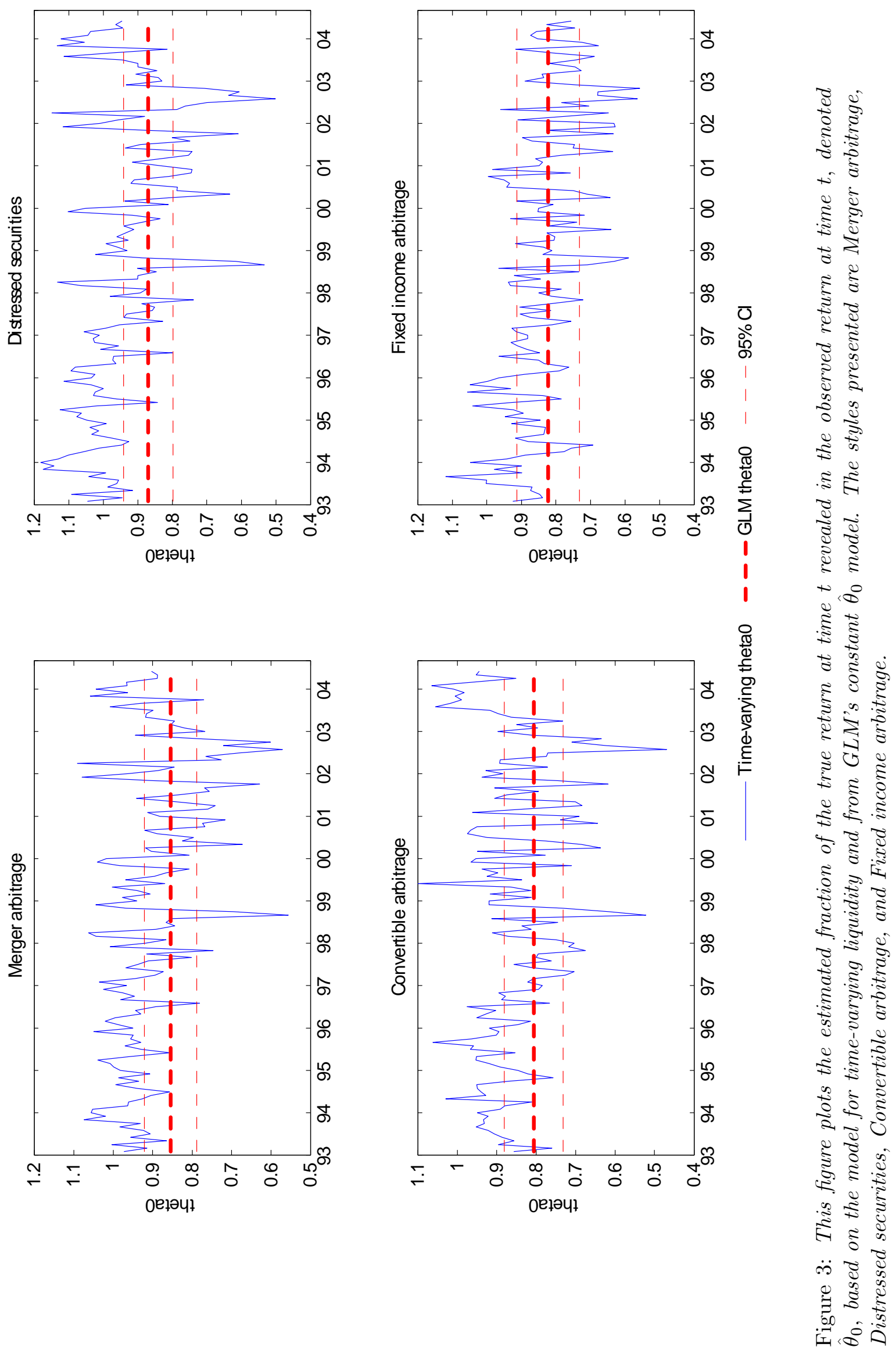